\title{
Characteristics of Explosive Cyclones over the Northern Pacific
}

\author{
SHUQIN ZHANG \\ Key Laboratory of Physical Oceanography, Ocean-Atmosphere Interaction and Climate Laboratory, \\ Department of Marine Meteorology, Ocean University of China, Qingdao, China
}

\section{GANG FU}

Key Laboratory of Physical Oceanography, Ocean-Atmosphere Interaction and Climate Laboratory, Department of Marine Meteorology, Ocean University of China, and Division of Oceanic Dynamics and Climate, Qingdao National Laboratory for Marine Science and Technology, Qingdao, China

\section{Chungu Lu}

National Science Foundation, Arlington, Virginia

\section{JINGWU LIU}

Key Laboratory of Physical Oceanography, Ocean-Atmosphere Interaction and Climate Laboratory, Department of Marine Meteorology, Ocean University of China, Qingdao, China

(Manuscript received 11 October 2016, in final form 24 October 2017)

\begin{abstract}
Explosive cyclones (ECs) over the northern Pacific Ocean during the cold season (October-April) over a 15-yr (2000-15) period are analyzed by using the Final (FNL) Analysis data provided by the National Centers for Environmental Prediction. These ECs are stratified into four categories according to their intensity: weak, moderate, strong, and super ECs. In addition, according to the spatial distribution of their maximum-deepening-rate positions, ECs are further classified into five regions: the Japan-Okhotsk Sea (JOS), the northwestern Pacific (NWP), the west-central Pacific (WCP), the east-central Pacific (ECP), and the northeastern Pacific (NEP). The occurrence frequency of ECs shows evident seasonal variations for the various regions over the northern Pacific. NWP ECs frequently occur in winter and early spring, WCP and ECP ECs frequently occur in winter, and JOS and NEP ECs mainly occur in autumn and early spring. The occurrence frequency, averaged maximum deepening rate, and developing and explosive-developing lifetimes of ECs decrease eastward over the northern Pacific, excluding JOS ECs, consistent with the climatological intensity distributions of the upper-level jet stream, midlevel positive vorticity, and low-level baroclinicity. On the seasonal scale, the occurrence frequency and spatial distribution of ECs are highly correlated with the intensity and position of the upper-level jet stream, respectively, and also with those of midlevel positive vorticity and low-level baroclinicity. Over the northwestern Pacific, the warm ocean surface also contributes to the rapid development of ECs. The composite analysis indicates that the large-scale atmospheric environment for NWP and NEP ECs shows significant differences from that for the 15-yr cold-season average. The southwesterly anomalies of the upper-level jet stream and positive anomalies of midlevel vorticity favor the prevalence of NWP and NEP ECs.
\end{abstract}

\section{Introduction}

An explosive cyclone (EC), also known as a meteorological bomb for its rapid intensification (see, e.g., Rice 1979), can potentially cause serious losses of life and property as a result of extremely bad weather such as severe winds, heavy precipitation, and so on. Some famous EC cases in history were the Queen Elizabeth II storm in 1978 (Gyakum

Corresponding author: Prof. Gang Fu, fugang@ouc.edu.cn 1983a,b, 1991) and the Presidents' Day cyclone in 1979 (Bosart 1981; Bosart and Lin 1984) over the Atlantic Ocean. Sanders and Gyakum (1980) defined an EC as a cyclone whose central sea level pressure (SLP) decreased at an average rate of at least 1 "bergeron":

$$
1 \text { bergeron }=(24 \mathrm{hPa} / 24 \mathrm{~h}) \times \sin 60^{\circ} / \sin \phi,
$$

where $\phi$ is the latitude of the cyclone center and $60^{\circ}$ is the adjusted latitude in geostrophically equivalent rate. 
Considering the averaged latitude of most rapid development of ECs and the temporal resolution of data, the definition of EC was slightly modified in later studies (Roebber 1984; Gyakum et al. 1989; Yoshida and Asuma 2004).

The climatological features of ECs over the Pacific and Atlantic Oceans had been investigated by subsequent studies (Sanders and Gyakum 1980; Roebber 1984; Sanders 1986; Gyakum et al. 1989; Chen et al. 1992; Sinclair 1997; Wang and Rogers 2001). The results consistently implied that EC was primarily a cold-season maritime phenomenon that frequently occurred over the midlatitude oceans, especially over the Kuroshio/ Kuroshio Extension and Gulf Stream (i.e., western boundary currents). The northwestern Pacific was one of the regions for most frequent occurrence of ECs. Chen et al. (1992) and Yoshida and Asuma (2004) further pointed out that the Japan Sea and the northwestern Pacific along the Kuroshio/Kuroshio Extension were two favorable areas for the rapid development of ECs. In addition, Iwao et al. (2012) found that the frequency of ECs had shown an increasing tendency in the northwestern Pacific in recent years.

The large-scale atmospheric and oceanic environments strongly influence the spatial distribution of ECs. The atmospheric conditions within and at the poleward side of the upper-level jet stream favored the rapid development of ECs (Sanders and Gyakum 1980; Uccellini et al. 1985; Kuwano-Yoshida and Asuma 2008). Sanders and Gyakum (1980) found that ECs usually occurred in the downstream side of a mobile 500-hPa trough, which was supported by Chen et al. $(1983,1985)$ and Chen et al. (1992). The Kuroshio/Kuroshio Extension in the northwestern Pacific also set a favorable oceanic environment for EC occurrence (Chen et al. 1992; Yoshiike and Kawamura 2009; Iizuka et al. 2013).

EC rapid development was considered to be influenced by several factors, such as the upper-level forcing (Rogers and Bosart 1986; Macdonald and Reiter 1988; Hirschberg and Fritsch 1991; Zehnder and Keyser 1991; Reader and Moore 1995), low-level baroclinicity (Wash et al. 1988; Manobianco 1989; Lim and Simmonds 2002; Seiler and Zwiers 2016), latent heat release (Gall 1976; Anthes et al. 1983; Emanuel et al. 1987; Mullen and Baumhefner 1988; Whitaker and Davis 1994; AhmadiGivi et al. 2004), and surface heat fluxes from the ocean (Chen et al. 1992; Kuwano-Yoshida and Asuma 2008; Yoshiike and Kawamura 2009; Kuwano-Yoshida and Enomoto 2013; Hirata et al. 2015). Their relative importance strongly depended on the intensity and region of ECs during their rapidly developing stage (Sanders and Davis 1988; Wash et al. 1988; Wang and Rogers 2001).
Sanders (1986) stratified ECs into three categories of intensity: weak (1.0-1.2 bergerons, moderate (1.3-1.8 bergerons), and strong ( $>1.8$ bergerons) ECs, and his results suggested that the 500-hPa absolute vorticity maxima and cyclonic vorticity advection varied with EC intensity. Yoshida and Asuma (2004) classified ECs over the northwestern Pacific into three types, depending on their positions of formation and rapid development, and many dynamical differences such as upper-level forcing and environmental baroclinicity were found among them. Notable divergences in the structures and development mechanisms of ECs for specific intensities and regions were also shown by many studies (Sanders and Davis 1988; Wash et al. 1988; Nuss and Kamikawa 1990; Bullock and Gyakum 1993; Gyakum and Danielson 2000; Wang and Rogers 2001).

Previous studies usually focused on ECs over the northwestern Pacific; ECs over the northern Pacific, especially over the northeastern Pacific, have received much less attention, although there have been a few papers that investigated ECs over the northeastern $\mathrm{Pa}$ cific (Murty et al. 1983; Danielson et al. 2006a,b). Allen et al. (2010) indicated that high-resolution reanalysis data could increase the climatological frequency of ECs, but the detailed statistical features of ECs over the northern Pacific have seldom been analyzed by using high-resolution reanalysis data in recent years. Moreover, it is also not clear how the large-scale atmospheric and oceanic environments influence the statistical features of ECs. Because there are many vital shipping lanes over the northern Pacific, it is very important to investigate the statistical features of ECs over the entire northern Pacific to avoid the threat of ECs to maritime safety.

This study investigates the characteristics of ECs over the northern Pacific during the cold season (October-April) over a 15-yr (2000-15) period. The purposes of the study are twofold: 1) to describe the more detailed statistical features of ECs over the northern Pacific by using reanalysis data with relatively high temporal and spatial resolution when compared with previous studies and 2) to investigate the influence of large-scale atmospheric and oceanic environments on the statistical features of ECs from a climate perspective. The paper is organized as follows: Section 2 describes the data and methods. Section 3 gives a modified definition of EC. Classifications of intensity and region are presented in section 4 . Section 5 reveals the statistical features of the types of ECs. Section 6 analyzes the relationships between large-scale atmospheric and oceanic environments with the occurrence frequency and spatial distribution of ECs. In section 7, a summary is given. 


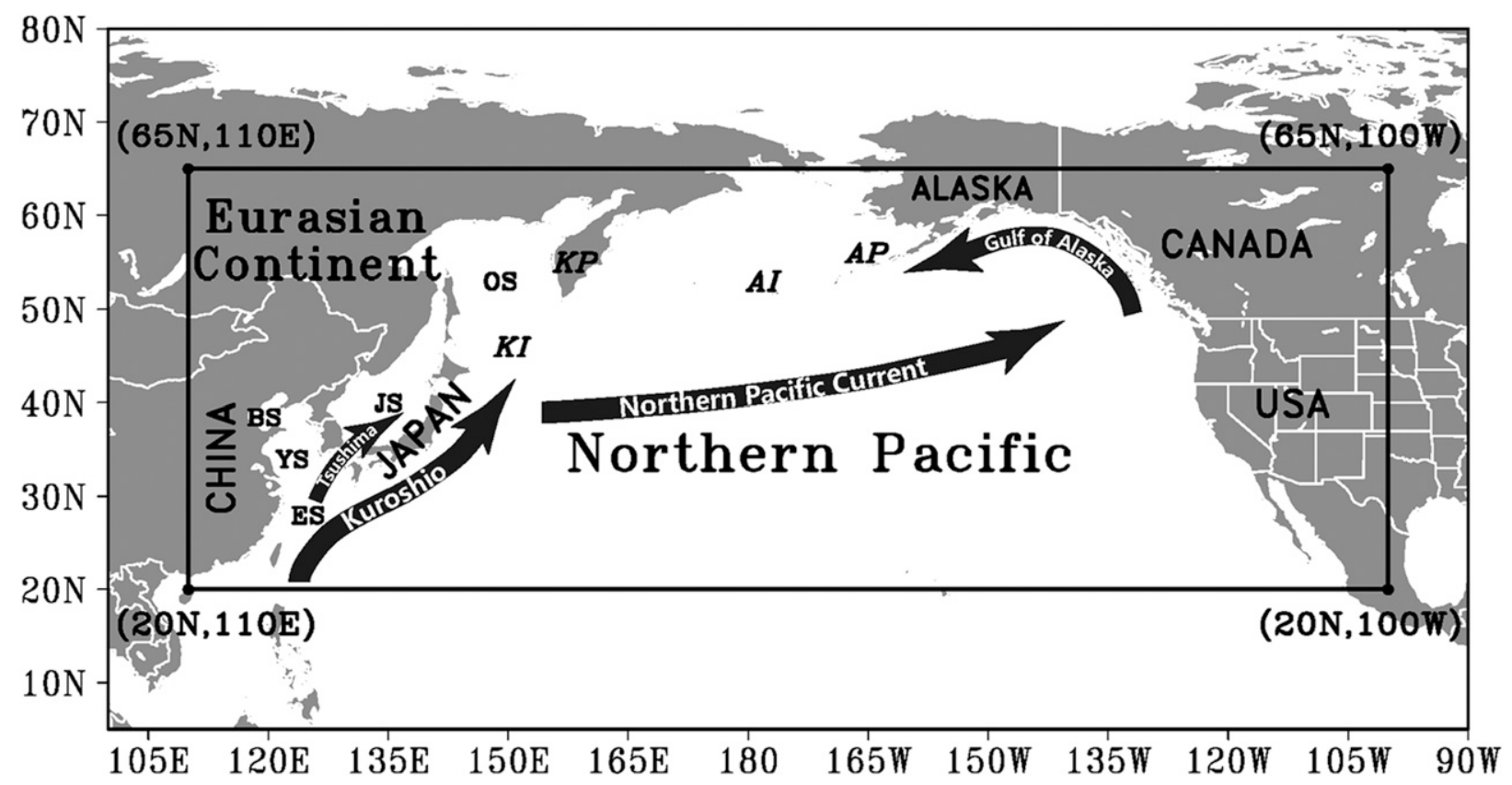

FIG. 1. Geographic map of the northern Pacific and the northern Pacific warm currents (heavy solid arrows). The outlined region indicates the study domain. Here BS is the Bohai Sea, YS is the Yellow Sea, ES is the East China Sea, JS is the Japan Sea, OS is the Okhotsk Sea, KI is the Kuril Islands, KP is the Kamchatka Peninsula, AI is the Aleutian Islands, and AP is the Alaska Peninsula.

\section{Data and method}

\section{a. Data}

We use the Final (FNL) Operational Global Analysis data (http://rda.ucar.edu/datasets/ds083.2/), provided by the National Centers for Environmental Prediction (NCEP), to identify ECs and examine the large-scale atmospheric environment. FNL data are on a $1^{\circ} \times 1^{\circ}$ horizontal resolution with 26 vertical levels from 1000 to $10 \mathrm{hPa}$ and are available four times per day at 0000, 0600, 1200, and 1800 UTC.

Advanced Very High Resolution Radiometer (AVHRR) infrared satellite sea surface temperature (SST) data (http://www.ncdc.noaa.gov/sst), provided by the National Climatic Data Center (NCDC, now known as the National Centers for Environmental Information) of the National Oceanic and Atmospheric Administration, are used to examine sea surface conditions. The AVHRR SST data are on a $0.25^{\circ} \times 0.25^{\circ}$ horizontal grid and 1-day temporal resolution.

\section{b. Method}

Although automatic detection and tracking algorithms of extratropical cyclones had been developed by Serreze (1995) for minimum central SLP and by Sinclair (1994) for vorticity centers, some errors usually were found for identifying extratropical cyclones (Wang and Rogers 2001; Allen et al. 2010). Neu et al. (2013) indicated that the results from 15 cyclone detection and tracking algorithms had important differences and could not judge which methods delivered incorrect results.

Therefore, we visually track cyclones in this paper to set up a more accurate database of ECs over the northern Pacific. Six-hourly surface weather charts with 1-hPa interval are constructed for tracking the cyclones in the deepening stage (from formation to minimum central SLP) lasting longer than $12 \mathrm{~h}$ within our study domain (Fig. 1). The center of a cyclone is defined as the grid position with minimum SLP within the innermost closed isobar. If only one cyclone at time step 2 appears within a $10^{\circ}$ latitude $\times 16^{\circ}$ longitude box centered on the cyclone at time step 1 , it is taken as the matching cyclone. If there are two or more cyclones found in the box at time step 2, the one with minimum SLP is used as the matching cyclone.

ECs are then identified from the obtained cyclones according to a modified version of the definition of EC from Sanders and Gyakum (1980), which is associated with the deepening rate of central SLP and will be elaborated in section 3. The deepening rate for each cyclone is calculated along its trajectory, and the cyclones with a maximum deepening rate that is larger than 1 bergeron are identified as ECs. The central SLP, maximum deepening rates, and trajectories for the identified ECs are recorded for further analysis. 
TABLE 1. The meridional distribution of MDPs according to the definition of EC given by Sanders and Gyakum (1980) and the modified definition given in this paper. The frequency shows the sum of MDPs within $5^{\circ}$-latitude bins.

\begin{tabular}{|c|c|c|c|c|c|c|c|c|c|}
\hline & \multicolumn{9}{|c|}{ Latitude bins $\left({ }^{\circ} \mathrm{N}\right)$} \\
\hline & $20-25$ & $25-30$ & $30-35$ & $35-40$ & $40-45$ & $45-50$ & $50-55$ & $55-60$ & $60-65$ \\
\hline & \multicolumn{9}{|c|}{ Sanders and Gyakum (1980) definition } \\
\hline Frequency & 0 & 3 & 51 & 209 & 243 & 190 & 51 & 13 & 1 \\
\hline \multirow[t]{2}{*}{ Percentage } & $0.00 \%$ & $0.39 \%$ & $6.70 \%$ & $27.46 \%$ & $31.93 \%$ & $24.97 \%$ & $6.70 \%$ & $1.71 \%$ & $0.13 \%$ \\
\hline & \multicolumn{9}{|c|}{ Modified definition of EC } \\
\hline Frequency & 0 & 2 & 53 & 194 & 244 & 193 & 77 & 18 & 2 \\
\hline Percentage & $0.00 \%$ & $0.26 \%$ & $6.77 \%$ & $24.78 \%$ & $31.16 \%$ & $24.65 \%$ & $9.83 \%$ & $2.30 \%$ & $0.26 \%$ \\
\hline
\end{tabular}

Wang and Rogers (2001) considered the merging and splitting cyclones as "parent cyclones." ECs that generate outside and inside the parent cyclones are treated as merging and splitting, respectively. The parent cyclones usually decay, whereas ECs generally deepen. Therefore, the parent cyclones are excluded in our study. The parent cyclone and EC rotate with each other cyclonically in the rapid-deepening stage of an EC, and the parent cyclone weakens until disappearance. Two examples are shown in the appendix (Figs. A1 and A2) so that readers may better understand the processes of merging and splitting.

Three key positions in the lifetime of EC are defined. 1) The initial formation position (IFP) is defined as the first position of an EC center where the SLP field has at least one closed isobar with 1-hPa intervals. 2) The maximum-deepening-rate position (MDP) is defined as the position of the EC centered over the 12-h interval of the most rapid deepening. For example, the position of maximum 12-h deepening is the position of the EC center at 0600 UTC, if the most rapid deepening occurs during the period from 0000 to 1200 UTC. 3) The minimum central SLP position (MCP) is defined as the position of an EC center with its minimum central SLP.

According to the deepening rate, the track of an EC from IFP to MCP is classified into three stages. 1) Preexplosive-developing track (PRET) is taken to be the track with a deepening rate that is smaller than 1 bergeron before explosive development. 2) Explosivedeveloping track (EXT) is taken to be the track with a deepening rate of larger than 1 bergeron. 3) Postexplosive-developing track (POET) is taken to be the track with a deepening rate that is smaller than 1 bergeron after explosive development.

\section{Modification of EC definition}

Previous studies had modified the adjusted latitude in geostrophically equivalent rate (Roebber 1984; Gyakum et al. 1989) or "dropped pressure" (Yoshida and Asuma 2004; Kuwano-Yoshida and Asuma 2008; Yoshiike and
Kawamura 2009) singly, depending on the definition of EC given by Sanders and Gyakum (1980). Given the facts that ECs usually occur in the midlatitudes and that the high-resolution reanalysis data are widely used, the adjusted latitude $\left(60^{\circ}\right)$ in geostrophically equivalent rate together with "24-h dropped pressure" should be modified objectively so as to describe the rapidly developing process more accurately.

The definition given by Sanders and Gyakum (1980) is primarily taken to identify ECs using the method as mentioned in section $2 \mathrm{~b}$ by modifying the calculation of deepening rate, and 761 cases are found. The top half of Table 1 summarizes the meridional distribution of MDPs within $5^{\circ}$-latitude bins. The frequency of MDPs peaks at $40^{\circ}-45^{\circ} \mathrm{N}$. Most MDPs $(84.4 \%)$ are concentrated in $35^{\circ}-50^{\circ} \mathrm{N}$, and only 17 cases $(2.2 \%)$ occur south of $30^{\circ} \mathrm{N}$ or north of $55^{\circ} \mathrm{N}$. The averaged latitude of MDPs is $42.7^{\circ} \mathrm{N}$. The results indicate that ECs frequently develop rapidly in the midlatitudes (Sanders and Gyakum 1980; Roebber 1984; Gyakum et al. 1989). The features of the meridional distribution of MDPs suggest that $45^{\circ} \mathrm{N}$ is more suitable for the adjusted latitude in geostrophically equivalent rate in Eq. (1).

Because the temporal resolution of the FNL data that are used in this study is $6 \mathrm{~h}$ rather than the $12 \mathrm{~h}$ that is used in Sanders and Gyakum (1980), "12-h dropped pressure" can capture the detailed development process of ECs. In this paper, 12-h SLP change is used to find an instance of the most rapid deepening in a cyclone's life. Therefore, the definition of EC given by Sanders and Gyakum (1980) is revised to be a cyclone whose central SLP decrease normalized at $45^{\circ} \mathrm{N}$ is greater than $12 \mathrm{hPa}$ within $12 \mathrm{~h}$. The deepening rate of cyclone SLP is calculated with the following formula:

deepening rate of cyclone SLP $\left(\mathrm{hPah}^{-1}\right)$

$$
=\left(\frac{P_{t-6}-P_{t+6}}{12}\right) \times\left(\frac{\sin 45^{\circ}}{\sin \frac{\phi_{t-6}+\phi_{t+6}}{2}}\right),
$$


where $t$ is time in hours, $P$ is the central SLP, and $\phi$ is the latitude of the cyclone center. Subscripts " $t-6$ " and " $t+6$ " represent variables of $6 \mathrm{~h}$ before and after present time $t$, respectively.

In total, 783 ECs (hereinafter when "all ECs" are mentioned it refers to this dataset) are found by using the above modified definition. The meridional distribution of their MDPs, as shown in the bottom half of Table 1, presents features that are similar to those that are based on the definition given by Sanders and Gyakum (1980) (Table 1, top half). The frequency of MDPs peaks at $40^{\circ}-45^{\circ} \mathrm{N}$ as well. MDPs are also concentrated in $35^{\circ}-50^{\circ} \mathrm{N}$, with $80.6 \%$. The averaged latitude of MDPs is $43.3^{\circ} \mathrm{N}$. These results suggest again that ECs frequently develop rapidly in the midlatitudes.

Although the total frequency of ECs identified by using the definition between the modification and Sanders and Gyakum (1980) does not change significantly, the detected cases show remarkable differences with $12.5 \%$ (98 cases), and the modified definition of EC can identify rapidly developing ECs within a short time. In addition, the spatial distribution of MDPs also shows obvious difference (not shown), with a shift in location to farther westward by using the modified definition. Moreover, the modified definition with 12-h dropped pressure and normalizing at $45^{\circ} \mathrm{N}$ results in an increased frequency of ECs ( 783 cases) relative to that obtained by using the definition given by Sanders and Gyakum (1980) (761 cases). This result suggests that the modified definition is suitable to describe more detailed processes of the rapid deepening of ECs, because the longer time period for pressure dropping in Sanders and Gyakum (1980) potentially smooths out the rapid development of ECs.

\section{Classification of ECs}

\section{a. Classification of intensity}

Previous studies had demonstrated that the structures and development mechanisms of ECs for a specific intensity showed notable divergences (Sanders and Davis 1988; Nuss and Kamikawa 1990; Bullock and Gyakum 1993; Gyakum and Danielson 2000). In this study, we find some "super" ECs, whose maximum deepening rate is much larger than the criterion of the strong EC $(>1.8$ bergerons) in Sanders (1986) (Fig. 3a). The most rapidly developing case occurred around 1200 UTC 14 January 2013, and its maximum deepening rate dramatically reached up to 3.07 bergerons. This fact implies that the structures and development mechanisms between strong and super ECs are potentially different and therefore need further investigation. Consequently, on the basis of classification in Sanders (1986), four
TABLE 2. The classification of intensity of ECs.

\begin{tabular}{lc}
\hline \hline Intensity & Deepening rate (bergerons) \\
\hline Weak & $1.00-1.29$ \\
Moderate & $1.30-1.69$ \\
Strong & $1.70-2.29$ \\
Super & $\geq 2.30$ \\
\hline
\end{tabular}

categories of intensity for ECs are more reasonable, according to the fact that some super cases occurred.

The $K$-means clustering algorithm is used to determine the threshold values between categories of intensity, which partitions a given dataset into a user-specified cluster $K$ by using the minimum-distance method. The results are shown in Table 2. ECs are classified into four categories of intensity: weak (1.00-1.29 bergerons), moderate (1.30-1.69 bergerons), strong (1.70-2.29 bergerons), and super ( $\geq 2.30$ bergerons) ECs. In addition to the fact that adding super ECs makes the classification of intensity more detailed, use of a $K$-means clustering algorithm to determine the threshold values between categories is considered to be more objective.

\section{b. Classification of regions}

In this study, the weighting factor in Cressman (1959) is used to smooth the spatial distribution of MDPs, which transforms the frequency of ECs at the irregularly spaced positions into data at the positions of a regularly arranged grid. The weighting factor is calculated by using the following formula:

$$
\begin{array}{llll}
W_{i, j}=\frac{R^{2}-r_{i, j}^{2}}{R^{2}+r_{i, j}^{2}} & \text { for } & r_{i, j}<R \\
W_{i, j}=0 & \text { for } & r_{i, j} \geq R,
\end{array}
$$

where $W_{i, j}$ is a weighting factor, $i$ and $j$ indicate the latitudinal and longitudinal grid point, $r$ is the distance between the EC center and the grid point, and the smoothing radius $R$ is set to be $5^{\circ}$. The frequency of ECs at every irregularly spaced position is 1 . The resolution of latitudinal and longitudinal grids is $1^{\circ} \times 1^{\circ}$.

Figure 2 shows the smoothed spatial distribution of MDPs. Five distinctive high-frequency centers are found: the central Japan Sea $\left(41.0^{\circ} \mathrm{N}, 135.0^{\circ} \mathrm{E}\right)$, the northwestern Pacific $\left(37.0^{\circ} \mathrm{N}, 144.5^{\circ} \mathrm{E}\right)$, the west-central Pacific $\left(45.5^{\circ} \mathrm{N}, 175.0^{\circ} \mathrm{E}\right)$, the east-central Pacific $\left(46.5^{\circ} \mathrm{N}, 167.5^{\circ} \mathrm{W}\right)$, and the northeastern Pacific $\left(48.5^{\circ} \mathrm{N}\right.$, $\left.142.5^{\circ} \mathrm{W}\right)$. Previous studies indicated that the structures and mechanisms of ECs over various regions showed significant differences stemming from local atmospheric and oceanic environments, especially at the maximumdeepening-rate moment (Wang and Rogers 2001; 


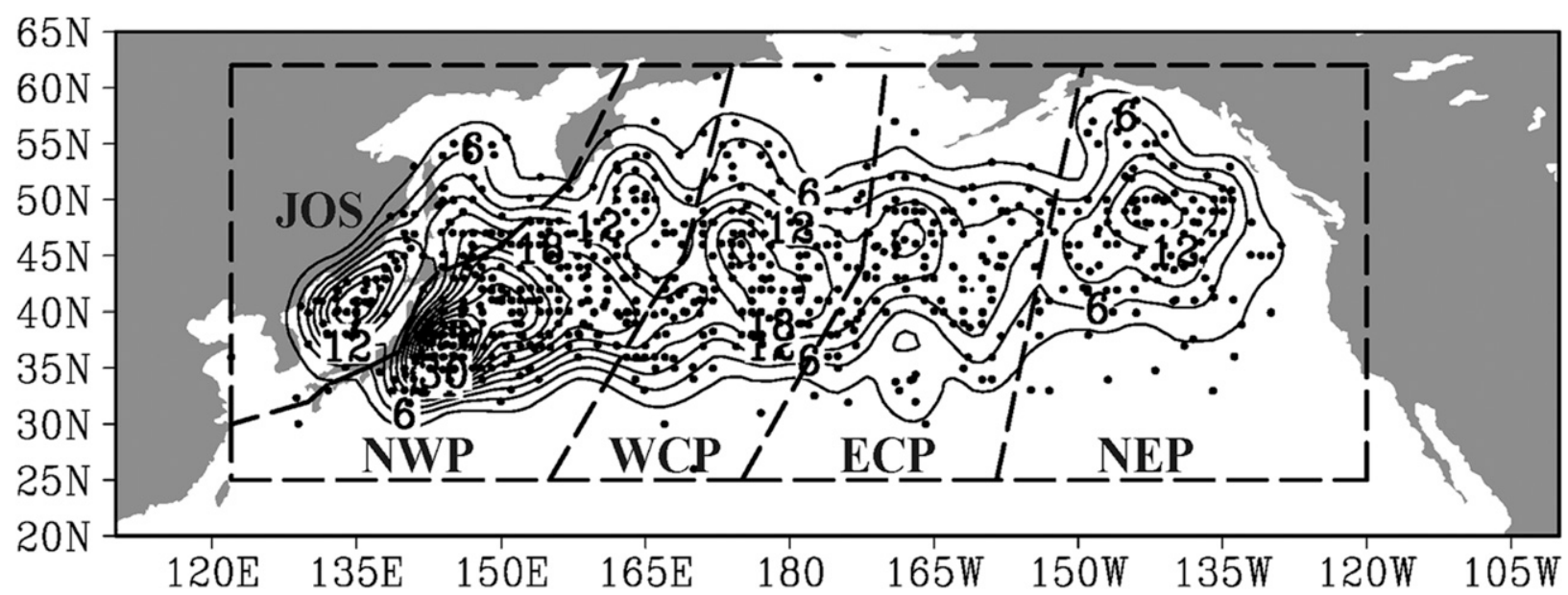

FIG. 2. The smoothed frequency (thin solid contours; contour interval = 3) of MDPs (dots) for all ECs. The boundaries of ECs for distinguishing the various regions are drawn with a thick dashed line.

Yoshida and Asuma 2004). Hence, the spatial distribution of MDPs is reasonable for taking as a basis for classification of regions.

The ECs over the northern Pacific are classified into five regions according to the spatial distribution of their MDPs for the five distinct high-frequency centers that are identified above; hereinafter we refer to them as the Japan-Okhotsk Sea (JOS), the northwestern Pacific (NWP), the west-central Pacific (WCP), the east-central Pacific (ECP), and the northeastern Pacific (NEP). The boundary between JOS and NWP ECs is the Japan Islands, Kuril Islands, and Kamchatka Peninsula. The boundaries for distinguishing other regions are determined by using two principles: 1) The dividing lines must be simple enough to distinguish ECs and 2) the lines should be located in areas with local minimum frequency. The five regions, as distinguished with dashed lines, are shown in Fig. 2.

\section{Statistical characteristics of ECs}

\section{a. The occurrence frequency and maximum deepening rate}

We identified 783 cases. Detailed information on strong and super ECs is in the appendix (Table A1). The occurrence frequency and percentage of ECs for the various regions and intensities are summarized in Table 3. It is seen that NWP ECs occur most frequently (274 cases), followed by WCP ECs (166 cases), ECP ECs (120 cases), NEP ECs (120 cases), and JOS ECs (103 cases). With the exception of JOS ECs, the occurrence frequency of ECs decreases as one moves eastward over the northern Pacific ( $t$ test of linear trend; 95\% confidence intervals).

Figure 3 shows the frequency distribution of maximum deepening rate for the various regions. The occurrence frequency of ECs decreases monotonically with intensity for all regions-more clearly for JOS and NEP ECs (Figs. 3b,f). The averaged maximum deepening rate of NWP ECs is the largest (1.44 bergerons), followed by WCP (1.41 bergerons), ECP (1.38 bergerons), NEP (1.34 bergerons), and JOS (1.27 bergerons) ECs. In addition, most strong and super ECs are in the NWP region ( $47.2 \%$ and $43.8 \%$, respectively), which suggests that strong and super ECs predominantly occur over the northwestern Pacific (Table 3). Those results indicate that in general NWP ECs develop most rapidly, followed by WCP, ECP, and NEP ECs, and that JOS ECs develop most slowly. It is interesting that the averaged deepening rate of ECs also decreases eastward

TABLE 3. The occurrence frequency (labeled FRE) and percentage (labeled PER) of ECs by region and intensity.

\begin{tabular}{|c|c|c|c|c|c|c|c|c|c|c|c|c|}
\hline \multirow[b]{2}{*}{ Categories } & \multicolumn{2}{|c|}{ All } & \multicolumn{2}{|c|}{ JOS } & \multicolumn{2}{|c|}{ NWP } & \multicolumn{2}{|c|}{ WCP } & \multicolumn{2}{|c|}{ ECP } & \multicolumn{2}{|c|}{ NEP } \\
\hline & FRE & PER & FRE & PER & FRE & PER & FRE & PER & FRE & PER & FRE & PER \\
\hline All & 783 & $100.00 \%$ & 103 & $13.15 \%$ & 274 & $35.00 \%$ & 166 & $21.20 \%$ & 120 & $15.33 \%$ & 120 & $15.33 \%$ \\
\hline Weak & 397 & $50.70 \%$ & 67 & $65.05 \%$ & 125 & $45.62 \%$ & 73 & $43.98 \%$ & 64 & $53.33 \%$ & 68 & $56.67 \%$ \\
\hline Moderate & 262 & $33.46 \%$ & 30 & $29.13 \%$ & 91 & $33.21 \%$ & 64 & $38.55 \%$ & 38 & $31.67 \%$ & 39 & $32.50 \%$ \\
\hline Strong & 108 & $13.79 \%$ & 4 & $3.88 \%$ & 51 & $18.61 \%$ & 26 & $15.66 \%$ & 16 & $13.33 \%$ & 11 & $9.17 \%$ \\
\hline Super & 16 & $2.04 \%$ & 2 & $1.94 \%$ & 7 & $2.55 \%$ & 3 & $1.81 \%$ & 2 & $1.67 \%$ & 2 & $1.67 \%$ \\
\hline
\end{tabular}



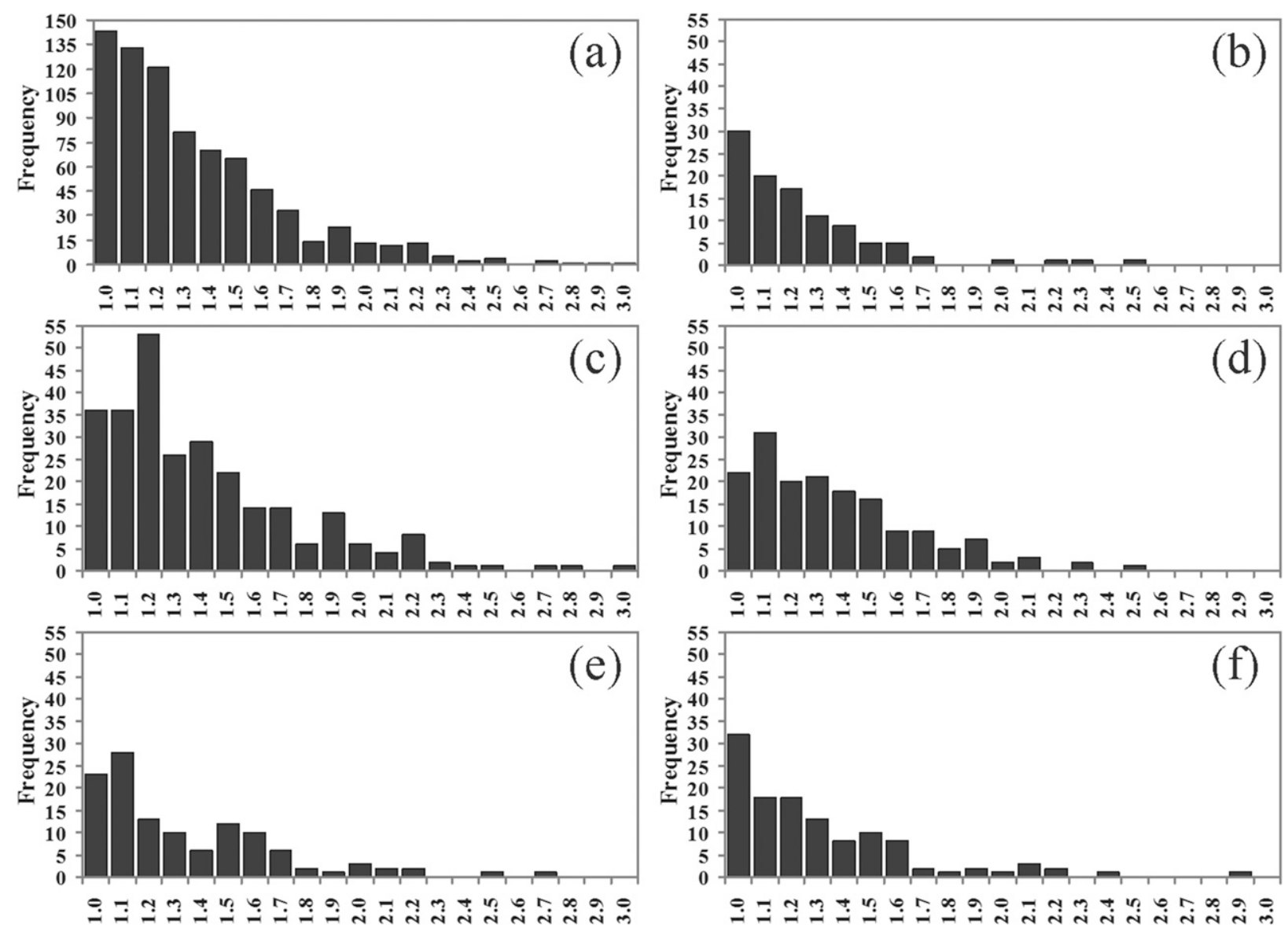

FIG. 3. Frequency of maximum deepening rate for (a) all, (b) JOS, (c) NWP, (d) WCP, (e) ECP, and (f) NEP regions' ECs. The horizontal axis shows the maximum deepening rate with 0.1 -bergeron intervals, and the vertical axis indicates the frequency of ECs.

over the northern Pacific, excluding JOS ECs ( $t$ test of linear trend; 99\% confidence intervals), which is similar to the feature of occurrence frequency of ECs.

\section{b. Seasonal variation}

Figure 4 illustrates the monthly frequency distribution of ECs for the various regions. Two peaks of monthly frequency for all ECs are identified: December and March (Fig. 4a). All ECs frequently occur in winter (from December to February) and early spring (March), with $69.2 \%$ of the cases. The monthly frequency patterns are different among the various regions. There are two peaks for the monthly frequency of JOS, NWP, and NEP ECs. These three regions share a similar peak in March and show a second peak in November, December, and October, respectively (Figs. 4b,c,f). There is a single peak for the monthly frequency of WCP and ECP ECs that occurs in January and December, respectively (Figs. 4d,e). Those results suggest that ECs frequently occur in winter and early spring for the combined data and the NWP region, JOS and NEP ECs mainly occur in autumn and early spring, and WCP and ECP ECs frequently occur in winter.

\section{c. The developing lifetime}

Table 4 shows the frequency of developing lifetime (measured in days) for the various regions. The developing lifetime is taken to be the time duration from IFP to MCP. More than $70 \%$ of ECs fall within a developing-lifetime span of 2.25 days for the various regions. The $70 \%$ concentration of developing lifetimes for NWP covers 1.25-3.50-day lifetimes, beginning at a duration that is 0.25 days longer than that for JOS, WCP, and ECP ECs (1.00-3.25 days) and 0.50 days longer than that for NEP ECs (0.75-3.00 days). The averaged developing lifetime for NWP ECs is the longest (2.63 days), followed by JOS (2.32 days), ECP (2.31 days), WCP (2.26 days), and NEP (1.85 days) ECs. These results indicate that ECs tend gradually to have shorter and shorter lifetimes from west to east over the 

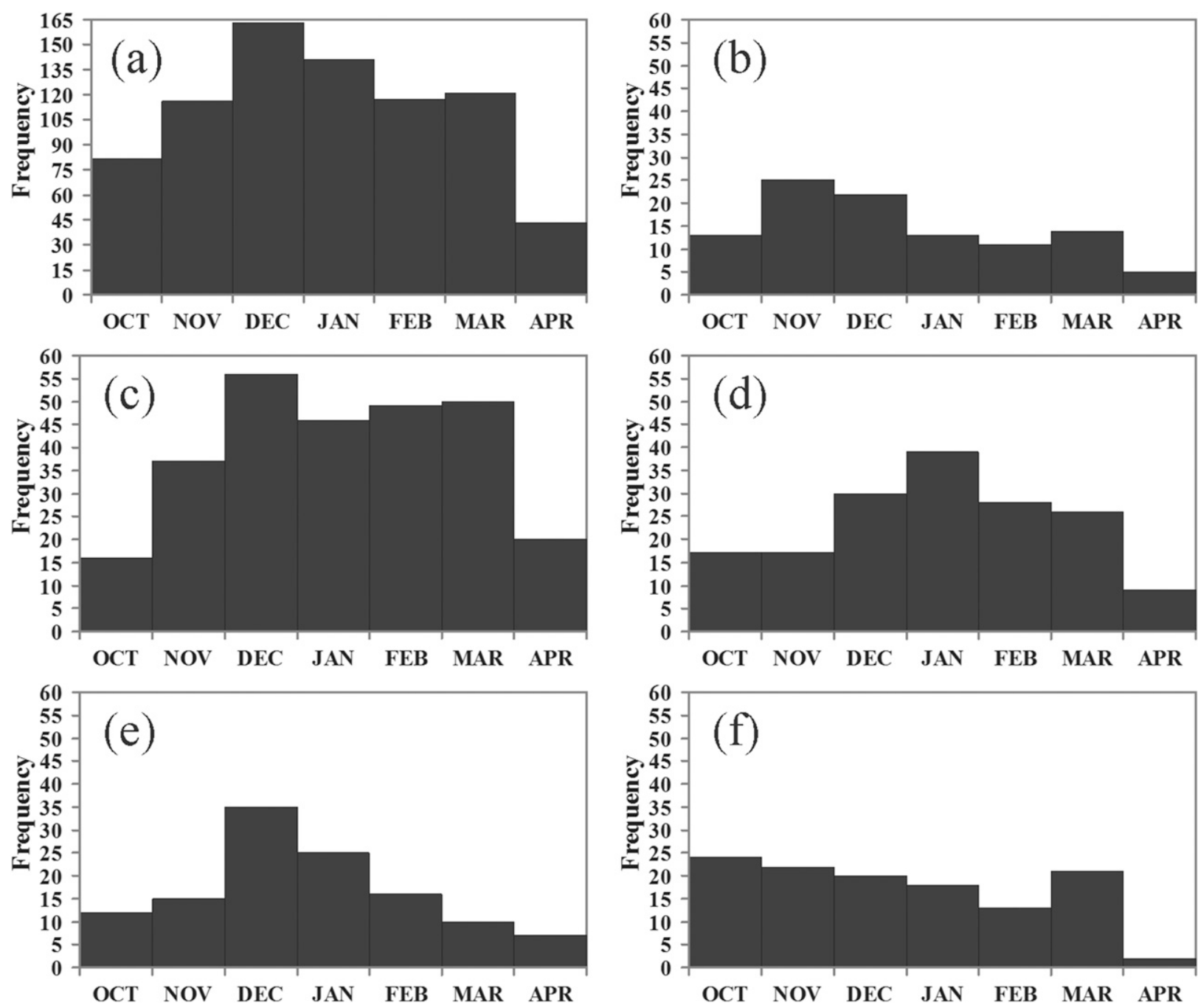

FIG. 4. The monthly frequency for (a) all, (b) JOS, (c) NWP, (d) WCP, (e) ECP, and (f) NEP regions' ECs. The horizontal axis shows the month, and the vertical axis indicates the frequency of ECs.

northern Pacific, with the exception of JOS ECs $(t$ test of linear trend; $98 \%$ confidence intervals).

\section{d. The explosive-developing lifetime}

Table 5 depicts the frequency of explosive-developing lifetime (also measured in days) for the various regions. The explosive-developing lifetime is taken as the time duration of the EXT stage. The frequency of ECs decreases monotonically with increasing explosivedeveloping lifetime for all regions. The explosivedeveloping lifetime with more than $70.0 \%$ of cases for all, WCP, and ECP regions' ECs is shorter than 1 day, whereas that for JOS and NEP ECs is shorter than 0.75 days (the shortest) and that for NWP ECs is shorter

TABLE 4. Frequency of ECs within different developing-lifetime ranges (in days) by region.

\begin{tabular}{|c|c|c|c|c|c|c|c|c|c|c|c|c|c|}
\hline & $0.50-0.75$ & $1.00-1.25$ & $1.50-1.75$ & $2.00-2.25$ & $2.50-2.75$ & $3.00-3.25$ & $3.50-3.75$ & $4.00-4.25$ & $4.50-4.75$ & $5.00-5.25$ & $5.50-5.75$ & $6.00-6.25$ & $6.50-6.75$ \\
\hline All & 40 & 116 & 137 & 145 & 112 & 109 & 62 & 29 & 14 & 12 & 2 & 3 & 2 \\
\hline JOS & 1 & 14 & 19 & 26 & 14 & 20 & 5 & 2 & 2 & 0 & 0 & 0 & 0 \\
\hline NWP & 5 & 14 & 44 & 59 & 46 & 47 & 34 & 13 & 4 & 5 & 1 & 1 & 1 \\
\hline WCP & 6 & 28 & 36 & 28 & 26 & 18 & 13 & 6 & 4 & 1 & 0 & 0 & 0 \\
\hline ECP & 4 & 28 & 23 & 16 & 13 & 16 & 6 & 5 & 4 & 4 & 0 & 0 & 1 \\
\hline NEP & 24 & 32 & 15 & 16 & 13 & 8 & 4 & 3 & 0 & 2 & 1 & 2 & 0 \\
\hline
\end{tabular}


TABLE 5. Frequency of ECs for different explosive-developing lifetimes (in days) by region.

\begin{tabular}{lrrrrrrr}
\hline \hline & 0.50 & 0.75 & 1.00 & 1.25 & 1.50 & 1.75 & 2.00 \\
\hline All & 241 & 230 & 136 & 101 & 45 & 20 & 10 \\
JOS & 40 & 41 & 12 & 7 & 2 & 1 & 0 \\
NWP & 67 & 65 & 51 & 43 & 26 & 13 & 9 \\
WCP & 47 & 46 & 34 & 25 & 7 & 6 & 1 \\
ECP & 36 & 38 & 24 & 14 & 8 & 0 & 0 \\
NEP & 51 & 40 & 15 & 12 & 2 & 0 & 0 \\
\hline
\end{tabular}

than 1.25 days (the longest). The averaged explosivedeveloping lifetime for all ECs is 0.84 days. That for NWP is the longest ( 0.97 days), followed by WCP (0.88 days), and ECP ECs (0.83 days); that for JOS and NEP ECs is the shortest (0.74 days). Therefore, the explosive-developing lifetime of NWP ECs is distinctly longer than that for other regions, followed by WCP, ECP, JOS, and NEP ECs. When excluding JOS ECs, the explosive-developing lifetime of ECs tends to be shorter and shorter from west to east over the northern Pacific ( $t$ test of linear trend; 99\% confidence intervals), which is similar to the pattern of developing lifetime indicated previously in section $5 \mathrm{c}$.

\section{e. The moving tracks}

Because the behavior of tracks is similar within a given region and is different across regions (not shown), the moving tracks of strong ECs for the various regions are taken to show their characteristics (Fig. 5). Strong JOS ECs generally form over continental East Asia and the northeastern coast of China, then develop explosively when they move from land or offshore to the Japan and Okhotsk Sea in a northeastward direction (Fig. 5a). The moving tracks of strong NWP ECs are also typically in a northeastward direction, and they mainly originate from the East China Sea, the body of water to the south and southeast of the Japan Islands (Fig. 5b). Strong NWP ECs travel along the axis of the Kuroshio/ Kuroshio Extension, consistent with previous studies (Sanders and Gyakum 1980; Gyakum et al. 1989; Chen et al. 1992). Strong WCP ECs usually form over the water to the east and southeast of the Japan Islands (Fig. 5c). They usually move eastward in their early stages and then turn northeastward in later stages with longer paths. Strong ECP ECs are mainly generated over the northwestern Pacific, and their moving tracks are similar to those of strong WCP ECs (Fig. 5d). Strong NEP ECs frequently form over the central and eastcentral Pacific (Fig. 5e). The moving tracks of strong NEP ECs originating from the central Pacific are similar to those of strong WCP ECs, whereas those strong NEP ECs forming over the east-central Pacific generally show short moving tracks in northeastward directions.

\section{Large-scale atmospheric and oceanic environments}

In section 5 , it was shown that the averaged maximum deepening rate and occurrence frequency of ECs decrease eastward over the northern Pacific, excluding JOS ECs. In addition, the occurrence frequency of ECs shows significant variations on the seasonal scale over the northern Pacific. To better understand the characteristics of large-scale atmospheric and oceanic environments for the eastward-decreasing trend of the occurrence frequency and averaged maximum deepening rate and the seasonal variations of occurrence frequency, the climatological distributions of the upper-level jet stream, midlevel positive vorticity, low-level baroclinicity, SST, and SST gradient associated with cyclone activities over the northern Pacific are investigated.

\section{a. Upper-level jet stream}

Because the upper-level forcing favors the rapid development of ECs (Uccellini and Kocin 1987; Wash et al. 1988; Wang and Rogers 2001; Yoshida and Asuma 2004), the upper-level jet stream is investigated to understand the upper-level larger-scale atmospheric environment for the occurrence frequency and spatial distribution of ECs (Fig. 6). The upper-level jet stream with wind speed greater than $60 \mathrm{~m} \mathrm{~s}^{-1}$ at $300 \mathrm{hPa}$ appears over the mid- and low-latitude northern Pacific, extending from the western Pacific to the east-central Pacific with an east-west orientation (Fig. 6a). The jet core is located to the south of the Japan Islands, and the wind speed decreases eastward. The high-frequency centers of all ECs predominantly appear at the poleward side of the jet axis. We have found that the occurrence frequency and averaged maximum deepening rate of ECs gradually decrease eastward over the northern Pacific (see section 5a). This eastwarddecreasing trend is correlated well with the decrease of jet stream intensity across the northern Pacific.

From October to April (Figs. 6b-h), ECs also mainly occur at the poleward side of the jet axis. Moreover, the occurrence frequency and spatial distribution of ECs present high correlations with the intensity and position of the jet stream on the seasonal scale, respectively. From October to January (Figs. 6b-e), the intensity of the jet stream gradually enhances from 45 to $75 \mathrm{~m} \mathrm{~s}^{-1}$ and the jet axis marches southward from $40^{\circ}$ to $30^{\circ} \mathrm{N}$. Correspondingly, the occurrence frequency of ECs increases and the spatial distribution of ECs shifts southward. Moreover, the spatial distribution of ECs tends to concentrate on the poleward side of the jet axis closely with the enhancement of the jet stream. From January to April (Figs. 6e-h), the jet stream shows the opposite 

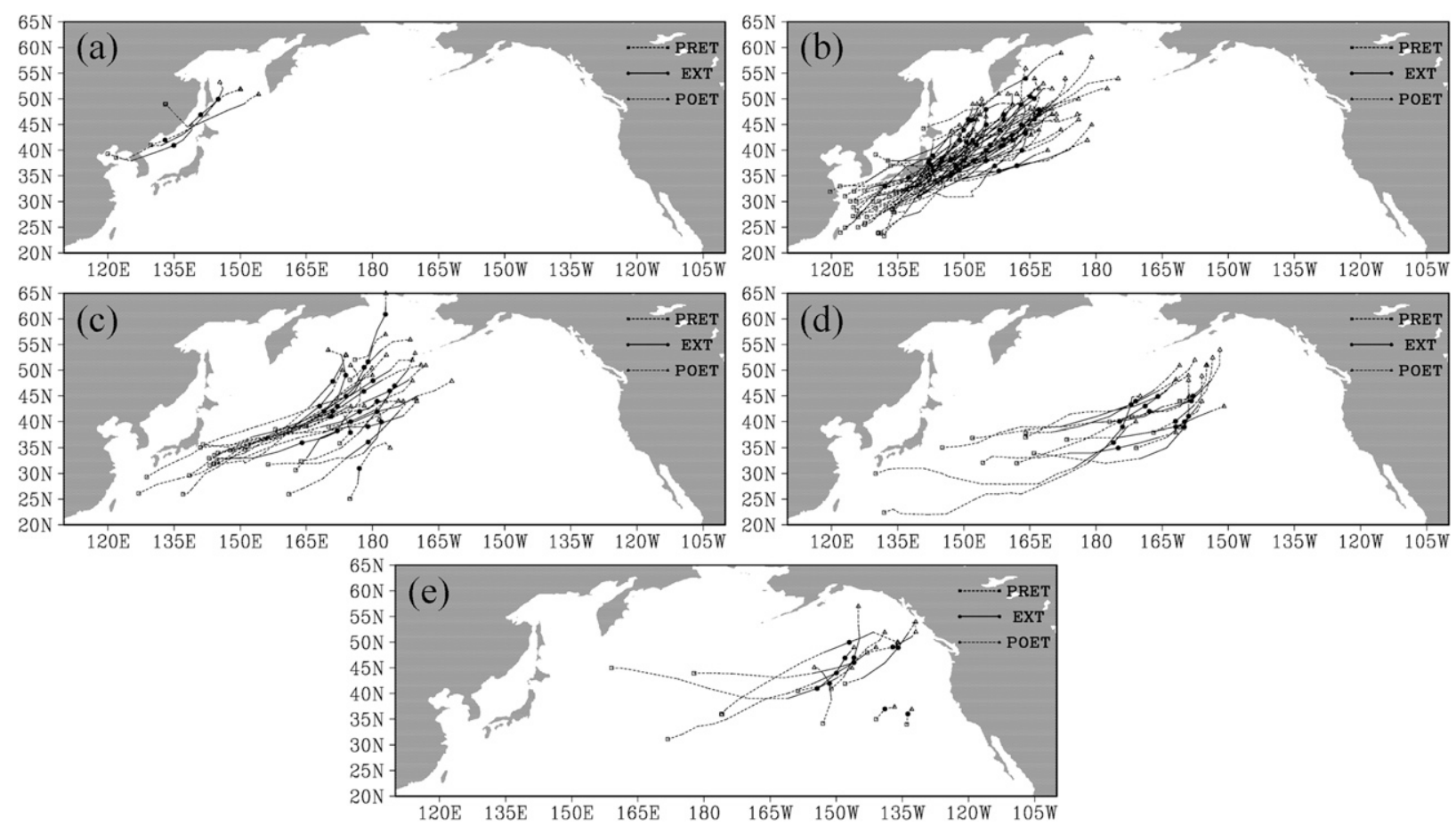

FIG. 5. The moving tracks of strong (a) JOS, (b) NWP, (c) WCP, (d) ECP, and (e) NEP ECs. Dashed lines with open squares indicate PRET, solid lines with filled circles indicate EXT, and dashed lines with open triangles indicate POET.

behavior: its intensity weakens gradually and its position shifts northward. The occurrence frequency and spatial distribution of ECs change in corresponding ways.

In particular, we have shown that JOS and NEP ECs frequently occur in autumn (see section 5 b), which perhaps results from the jet stream being located farther north and extending to the northeastern Pacific, respectively, during that period. The jet stream cannot explain why the high-frequency center of MDPs over the northeastern Pacific appears in March, however. The morphological feature of the jet stream shows notable differences in October from that in other months, which is associated with an anticyclonic curve to the eastern coast of the Japan Islands. The left-front region of the jet stream with an anticyclonic curve is unfavorable for the rapid development of ECs, with the result that few ECs occur over there in October (see the discussion in the next paragraph).

Although the fact that ECs frequently occur at the poleward side of a jet axis had been demonstrated by previous studies (Sanders and Gyakum 1980; Wash et al. 1988; Yoshida and Asuma 2004), it had not been revealed that the occurrence frequency and spatial distribution of ECs are highly correlated with the intensity and position of the upper-level jet stream, respectively, on the seasonal scale. This study demonstrates clearly that the upper-level jet stream plays an important role in controlling the occurrence frequency and spatial distribution of ECs over the northern Pacific. The divergence center and the positive vorticity advection usually appeared in the left-front region of straight or cycloniccurved jet streams (Uccellini and Kocin 1987; Wash et al. 1988; Cammas and Ramond 1989; Nakamura 1993), which were strongly related to surface cyclogenesis (Keyser and Shapiro 1986; Wash et al. 1988). This upper-level atmospheric environment results in ECs frequently occurring in the left-front region of straight or cyclonic-curved jet streams. In addition, $\mathrm{Ziv}$ and Paldor (1999) indicated that the convergence center usually appeared in the exit region of the anticycloniccurved jet stream, which may explain why ECs occur rarely off the eastern coast of the Japan Islands in October.

\section{b. Midlevel positive vorticity}

Subsequent studies emphasized that midtropospheric conditions, such as troughs, positive vorticity, and positive vorticity advection, were the important factors for the rapid development of ECs (Sanders and Gyakum 1980; Sanders 1986; Wash et al. 1988; Lupo et al. 1992; Azad and Sorteberg 2014); the midlevel positive vorticity is analyzed to examine the midtropospheric condition for the occurrence frequency and spatial distribution of ECs (Fig. 7). A zonal belt with large 

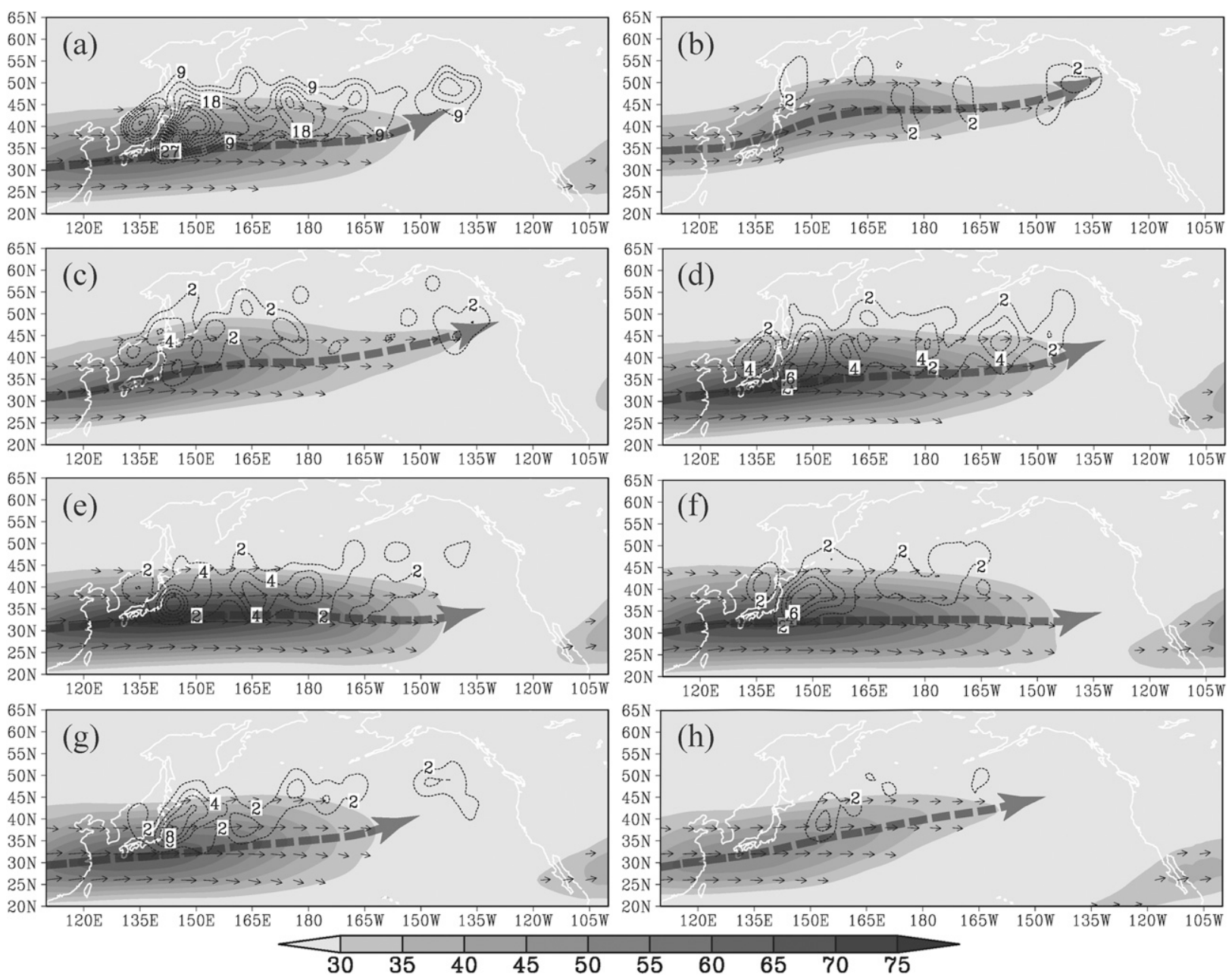

FIG. 6. Time-mean charts of the 300 -hPa jet stream (shaded, with $\geq 30$ and $5 \mathrm{~m} \mathrm{~s}^{-1}$ intervals), jet axis (thick dashed arrow), and horizontal wind vector (thin solid arrows, showing $\geq 30 \mathrm{~m} \mathrm{~s}^{-1}$ ) for (a) the cold season, (b) October, (c) November, (d) December, (e) January, (f) February, (g) March, and (h) April. The dashed contours indicate the smoothed frequency of ECs [ $\geq 9$ with a contour interval of 3 in (a), and $\geq 2$ with a contour interval of 2 in (b)-(h)].

positive vorticity at $500 \mathrm{hPa}$ is found over the mid- and high-latitude northern Pacific (Fig. 7a), with a major center over the northwestern Pacific and a minor center over the northeastern Pacific. The high-frequency centers of all ECs are located within and at the equatorward side of the belt with large positive vorticity.

On the seasonal scale, the occurrence frequency and spatial distribution of ECs are also highly correlated with the intensity and position of positive vorticity, respectively. From October to January (Figs. 7b-e), the center of positive vorticity over the northeastern Pacific weakens. Consistent with that, the occurrence frequency of ECs over there decreases gradually, while the positive vorticity with a center over the northwestern Pacific is enhanced and its location shifts southward gradually. Meanwhile, the occurrence frequency of ECs increases and the spatial distribution of ECs shifts southward over the northwestern Pacific as well. From January to April (Figs. 7e-h), the seasonal variations of occurrence frequency and spatial distribution of ECs also follow the intensity and position of positive vorticity, respectively, but the occurrence frequency decreases and the spatial distribution shifts northward gradually, in contrast to those features from October to January.

The results show that the occurrence frequency and spatial distribution of ECs present high concordance with the intensity and position of positive vorticity, respectively, on the seasonal scale. Sanders (1986) pointed out that the positive vorticity had an important influence on the occurrence of ECs. Subsequent studies had revealed that positive vorticity advection was the major forcing process in the rapid development of ECs 

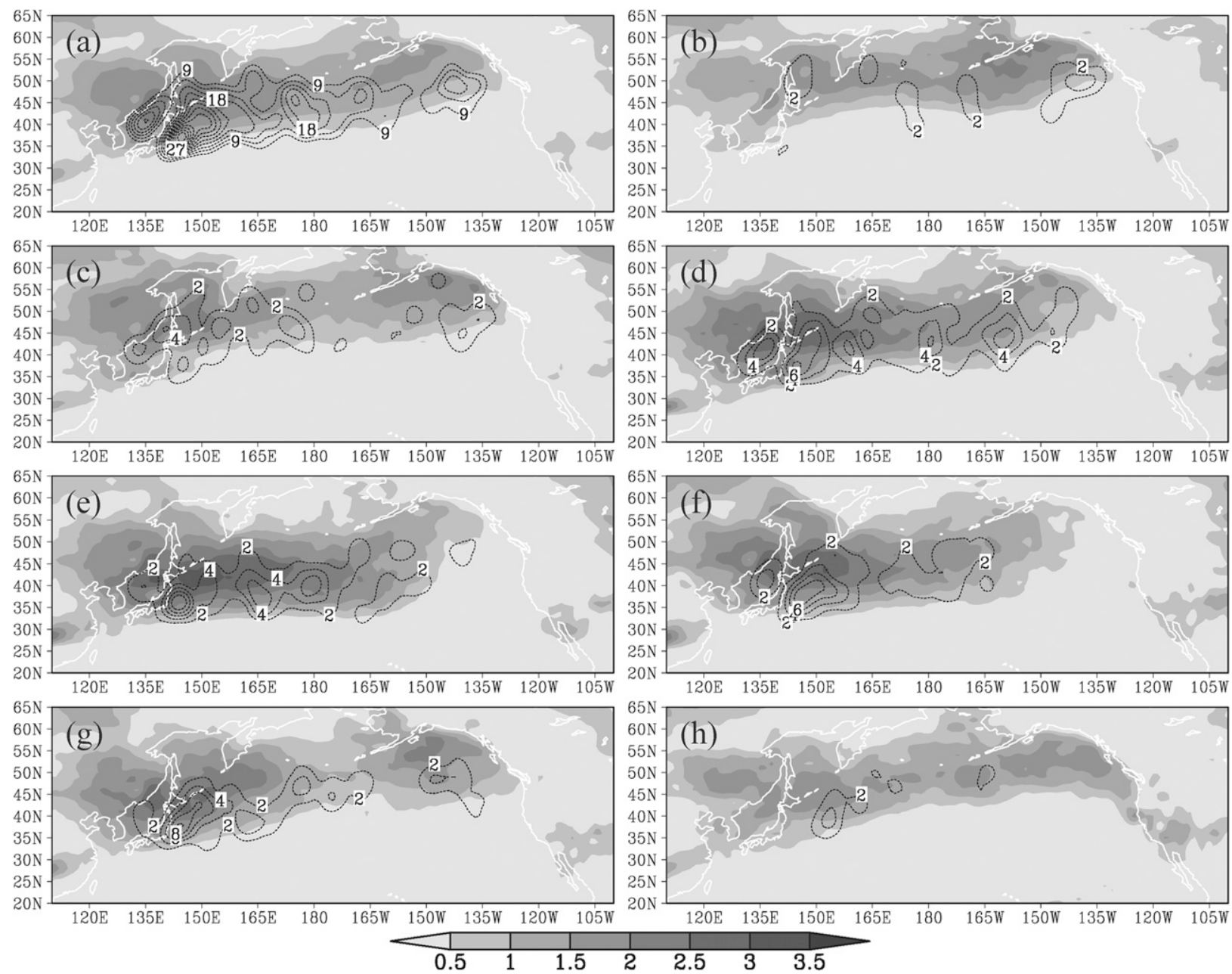

FIG. 7. As in Fig. 6, but for 500-hPa positive vorticity (shaded, with $0.5 \times 10^{-5} \mathrm{~s}^{-1}$ intervals).

(Wash et al. 1988; Lupo et al. 1992; Azad and Sorteberg 2014). The positive-vorticity-associated westerly flow at $500 \mathrm{hPa}$ usually makes positive vorticity advection appear over the high-frequency regions of ECs, which favors the frequent occurrence of ECs. Thus, positive vorticity has significant influence on the occurrence frequency and spatial distribution of ECs over the northern Pacific.

\section{c. Low-level baroclinicity}

ECs generally had a remarkable baroclinic zone at low level during their rapid-development stages (Bosart and Lin 1984; Rogers and Bosart 1986; Sanders and Davis 1988; Kuwano-Yoshida and Asuma 2008). Figure 8 shows the time-mean low-level baroclinicity. Strong low-level baroclinicity, which is represented by the horizontal gradient of potential temperature, exists over the midlatitude northern Pacific and is centered over the northwestern Pacific (Fig. 8a). The high-frequency centers of all ECs predominantly appear over the belt of strong low-level baroclinicity. The low-level baroclinicity decreases eastward across the northern Pacific; this is correlated with the eastward decreasing trend of the occurrence frequency and averaged maximum deepening rate of ECs. In each month (Figs. 8b-h), ECs also mainly occur over the belt of strong low-level baroclinicity. From October to January (Figs. 8b-e), low-level baroclinicity is enhanced slowly from $1.0 \times 10^{-5}$ to $1.2 \times 10^{-5} \mathrm{~K} \mathrm{~m}^{-1}$ and its location shifts southward slightly, whereas from January to April (Figs. 8e-h), the features of low-level baroclinicity show the opposite behavior. It is seen that the occurrence frequency and spatial distribution of ECs coincide with the intensity and position of low-level baroclinicity, respectively, on the seasonal scale. These results indicate that low-level baroclinicity has significant effects on the occurrence frequency and spatial distribution of ECs over the northern Pacific.

In addition, low-level baroclinicity over the northwestern Pacific is stronger than that over the northeastern 

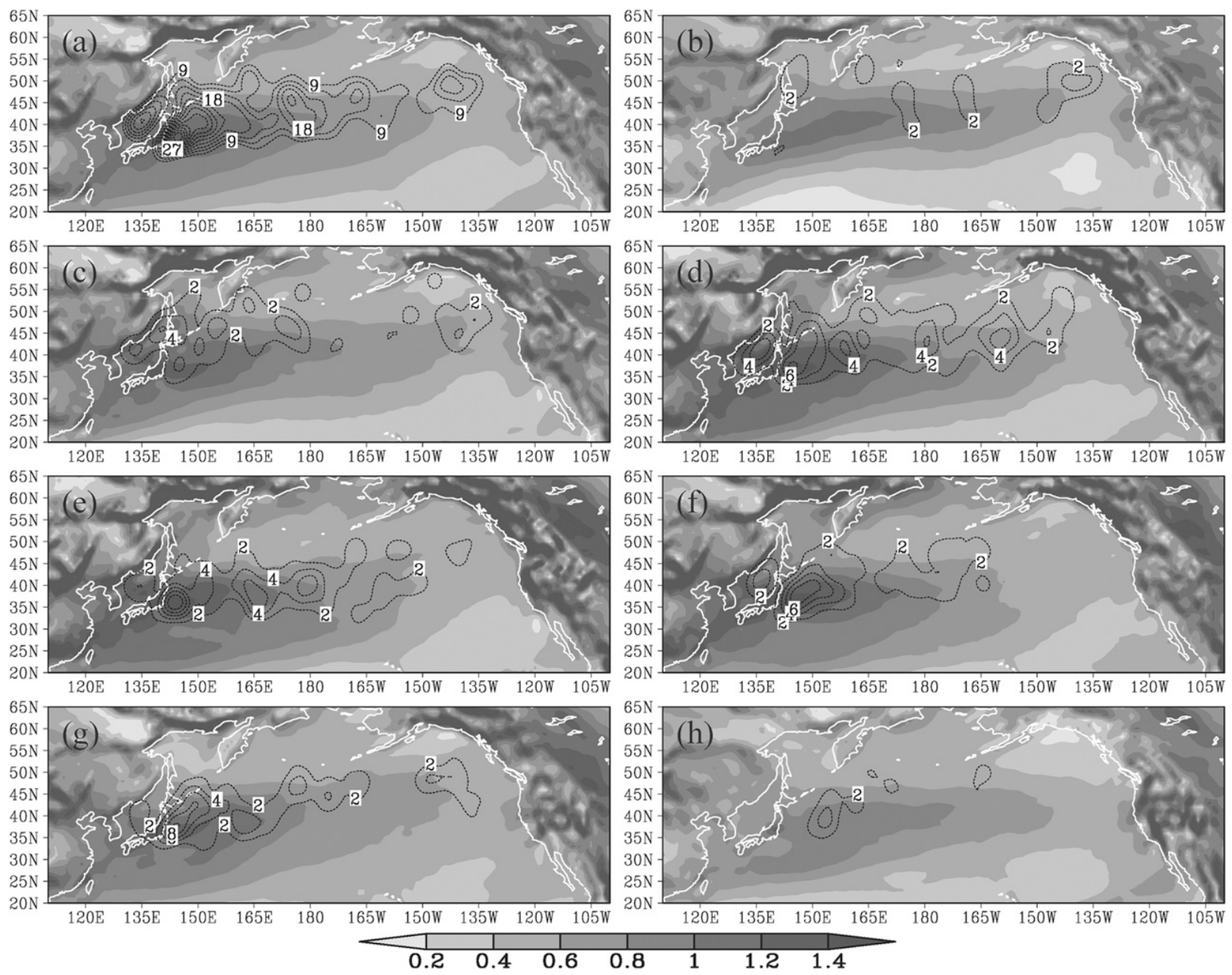

FIG. 8. As in Fig. 6, but for potential temperature gradient (shaded, with $0.2 \times 10^{-5} \mathrm{~K} \mathrm{~m}^{-1}$ intervals).

Pacific, and low-level baroclinicity changes evidently over the northwestern Pacific and insignificantly over the northeastern Pacific on the seasonal scale. Yoshida and Asuma (2004) showed that ECs over the northwestern Pacific had a strong baroclinic zone at low or midlevels resulting from the presence and extension of the cold air mass from the Eurasian continental area while the oceanic air mass is relatively uniform over the northeastern Pacific, leading to weak baroclinicity. These results indicate that low-level baroclinicity has stronger effects on ECs over the northwestern Pacific than on those over the northeastern Pacific.

\section{d. SST and SST gradient}

The Kuroshio, North Pacific Current, and Gulf of Alaska are three significant warm currents in the northern Pacific (Fig. 1). Because the oceanic environment is considered to be crucial for the rapid development of ECs (Chen et al. 1983, 1985; Kuo et al. 1991a;
Yoshiike and Kawamura 2009; Iizuka et al. 2013), the time-mean SST gradient (Fig. 9) and surface heat fluxes (Fig. 10) over the northern Pacific are analyzed. As a whole, the high-frequency centers of all ECs are located over the belt of strong SST gradient. Although the seasonal variations of SST and SST gradient are insignificant over the northern Pacific (Figs. 9b-h), the surface sensible and latent heat fluxes present evident differences on the seasonal scale over the northwestern Pacific (Figs. 10b-h). The surface sensible and latent heat fluxes increase from October to January and decrease from January to April. They reach a maximum in winter, resulting from the southward intrusion of cold air. In the northeastern Pacific, the surface sensible and latent heat fluxes are small, however, and their variations are insignificant on the seasonal scale.

In the vicinity of the northwestern Pacific, ECs tend to concentrate over the Kuroshio/Kuroshio Extension, which implies that the warm ocean current plays a key 

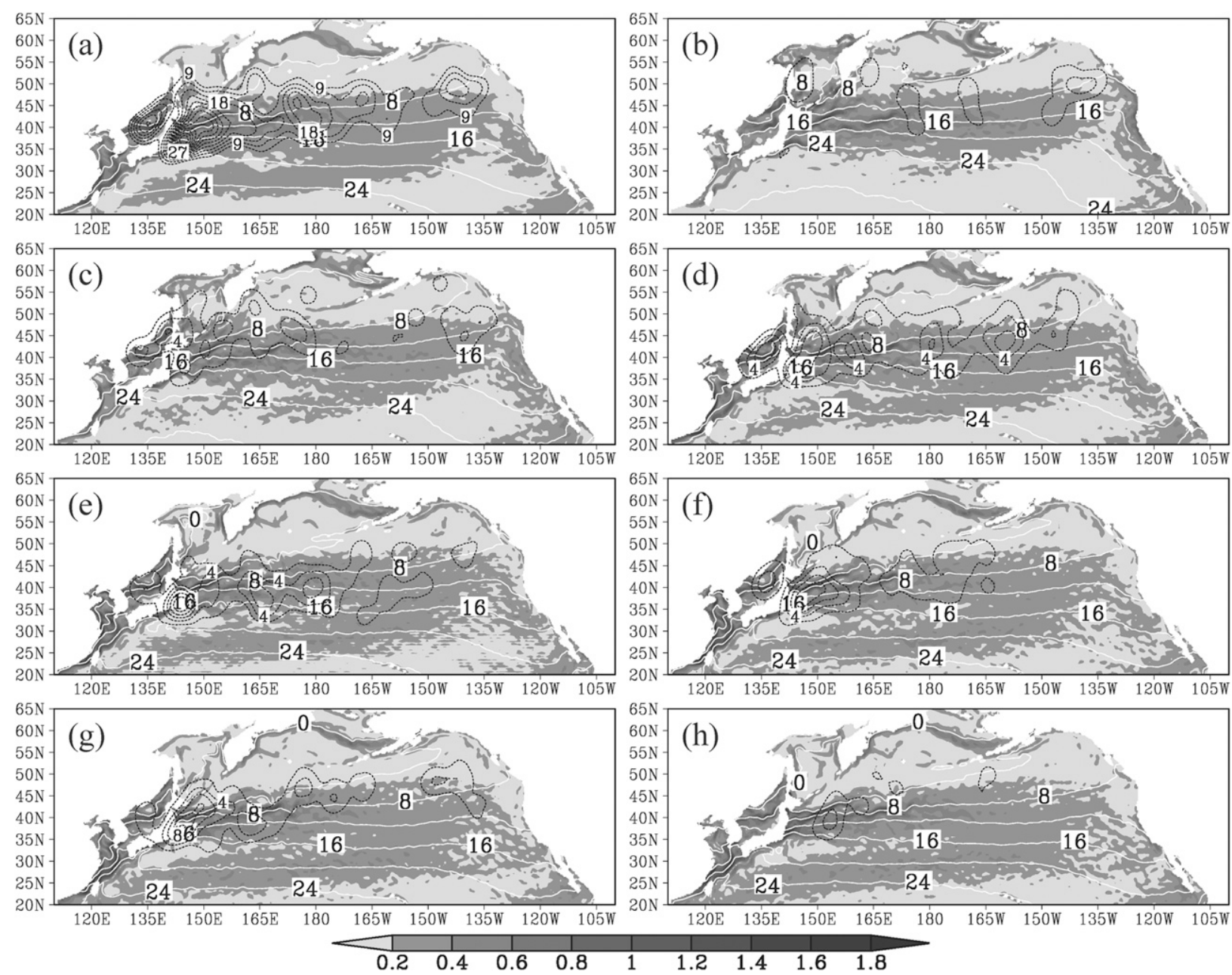

FIG. 9. As in Fig. 6, but for SST (white contours, with $4^{\circ} \mathrm{C}$ intervals) and SST gradient (shaded, with $0.2 \times 10^{-4}{ }^{\circ} \mathrm{C} \mathrm{m}{ }^{-1}$ intervals).

role in the rapid development of ECs (Chen et al. 1992; Yoshiike and Kawamura 2009; Hirata et al. 2015). The warm ocean current supplied a large amount of sensible and latent heat fluxes to the midlatitude atmosphere (Kelly et al. 2010; Kwon et al. 2010). Abundant sensible and latent heat fluxes contributed to facilitating rapid intensification of ECs (Davis and Emanuel 1988; Kuwano-Yoshida and Asuma 2008; Kuwano-Yoshida and Enomoto 2013), through destabilizing the lower atmosphere and increasing latent heat release (Kuo et al. 1991a,b; Neiman and Shapiro 1993; Reed et al. 1993; Takayabu et al. 1996; Booth et al. 2012). Consequently, a large amount of surface heat fluxes from the Kuroshio/Kuroshio Extension provide a favorable oceanic environment for the rapid development of ECs, resulting in the frequent occurrence of ECs over the northwestern Pacific.

Although the North Pacific Current and Gulf of Alaska exist over the midlatitude eastern Pacific, they are weaker than the Kuroshio/Kuroshio Extension. Meanwhile, ECs developing rapidly over the northeastern Pacific generally originate from the adjacent low-latitude ocean with shorter trajectories or from the northwestern Pacific with longer trajectories. The former ECs at low level already have similar properties to the ocean when they form. The latter ECs experience airmass modification when they move from the northwestern Pacific to the northeastern Pacific with longer tracks. The weaker warm ocean currents and similar properties between air and sea surface result in surface heat fluxes that are weaker, and their variations are indistinct on the seasonal scale over the northeastern Pacific, which suggests that warm ocean currents associated with surface heat fluxes have a weak influence on the rapid development of ECs over the northeastern Pacific.

The above results indicate that the large-scale atmospheric and oceanic environments have a significant 

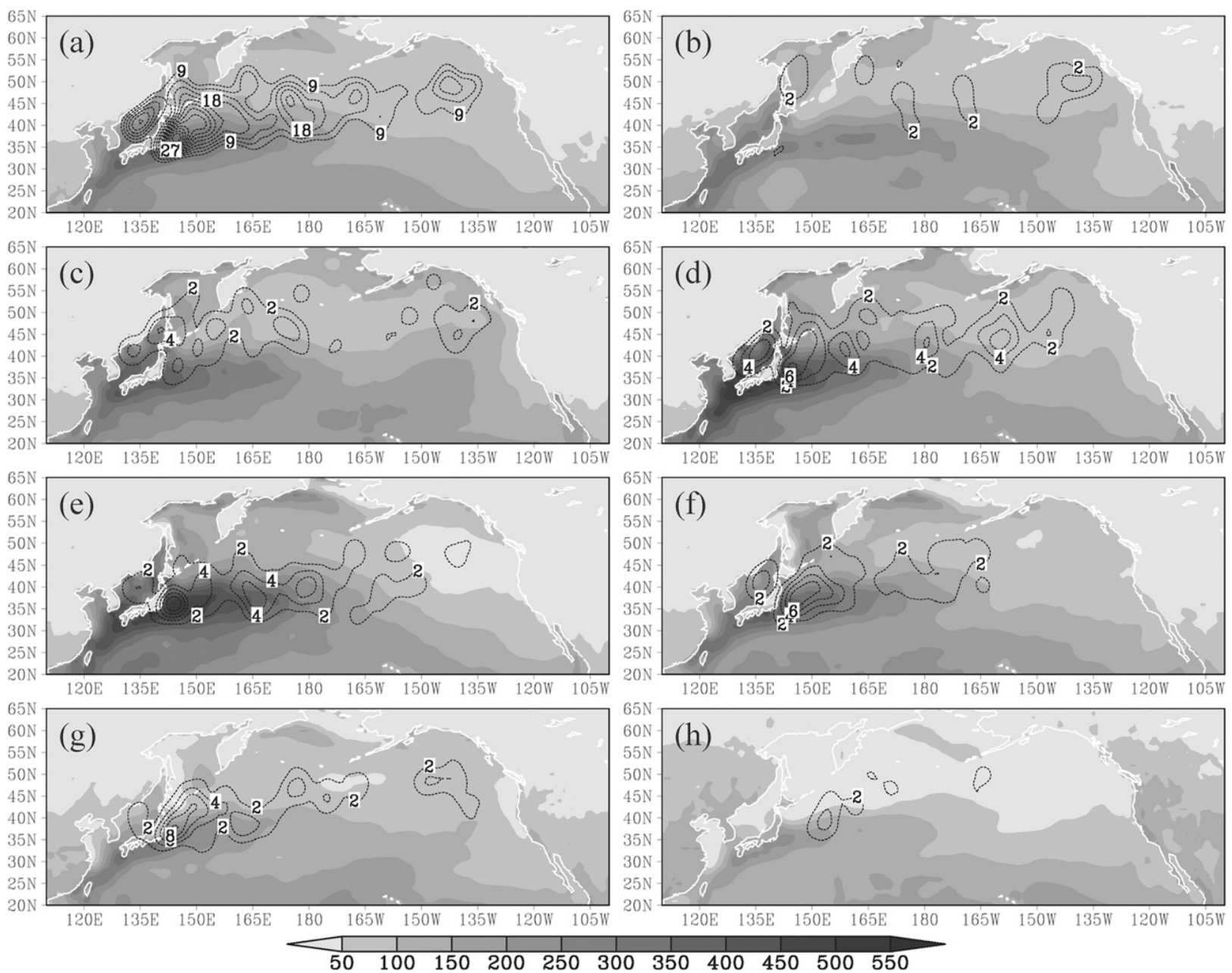

FIG. 10. As in Fig. 6, but for surface heat fluxes (the sum of surface sensible heat fluxes and surface latent heat fluxes) (shaded, with $50 \mathrm{~W} \mathrm{~m}^{-2}$ intervals).

influence on EC activity on the seasonal scale. In addition, in spatial distribution, the upper-level jet stream, midlevel positive vorticity, low-level baroclinicity, and surface heat fluxes consistently decrease eastward in the cold season. In seasonal variation, they consistently are located southward and are much stronger in winter. These results suggest that the large-scale atmospheric and oceanic environments between upper level and low level exhibit a close connection, especially over the northwestern Pacific. The surface heat fluxes from the Kuroshio/Kuroshio Extension can maintain low-level baroclinicity over the northwestern Pacific (Hoskins and Valdes 1990; Hotta and Nakamura 2011). Low-level baroclinicity drives the East Asian subtropical westerly jet at the upper level through the thermal wind. The upper-level jet stream associated with positive vorticity affects midtropospheric conditions. The combination of these large-scale atmospheric and oceanic environments results in the characteristics of the eastward-decreasing trend of the occurrence frequency and averaged maximum deepening rate as well as the seasonal variations of occurrence frequency and spatial distribution of ECs. In addition, Nakamura (1992) pointed out that the storm track over the northern Pacific was dominant in late autumn and early spring on the seasonal scale, which is distinct from the most frequent ECs in winter. This different seasonality between storm track and EC is probably due to the difference in their definitions. Moreover, Chen et al. (1991) also indicated that cyclogenesis over the northwestern Pacific occurred only in the cold season, which was related to the development of ECs.

\section{e. Composite analyses for NWP and NEP ECs}

NWP ECs occur most frequently, and NEP ECs have received much less attention in previous studies. Therefore, to better understand the characteristics of 

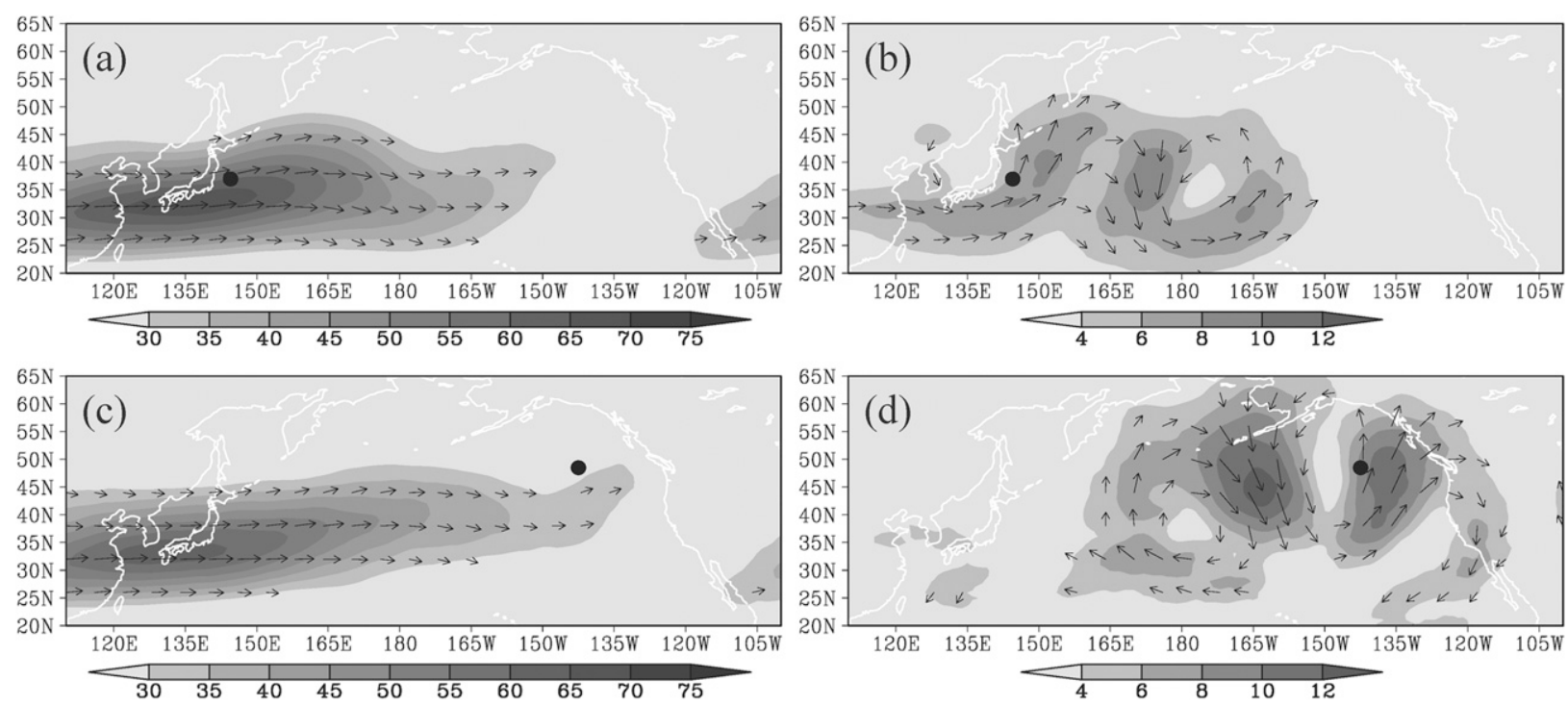

FIG. 11. Composite charts of the $300-\mathrm{hPa}$ jet stream (shaded, with $\geq 30$ and $5 \mathrm{~m} \mathrm{~s}^{-1}$ intervals) and horizontal wind vector (arrows, showing $\geq 30 \mathrm{~m} \mathrm{~s}^{-1}$ ) for (a) NWP and (c) NEP ECs. Also shown are the anomalies of jet stream (shaded, with $\geq 4$ and $2 \mathrm{~m} \mathrm{~s}$ intervals) and horizontal wind vector (arrows, showing $\geq 4 \mathrm{~m} \mathrm{~s}^{-1}$ ) for (b) NWP and (d) NEP ECs. The dot indicates the highfrequency center.

favorable large-scale atmospheric environment for the frequent occurrence of NWP and NEP ECs, a composite analysis by using geographically fixed coordinates is conducted. NWP and NEP ECs that occur during the 15-yr cold seasons are employed in the composite analysis. The key time examined in the composite analysis for the jet stream is the time of maximum deepening rate, and that for positive vorticity is $6 \mathrm{~h}$ before the time of the maximum deepening rate. Furthermore, the anomaly fields between the composite fields and the 15-yr cold-season averaged fields are prepared for NWP and NEP ECs, respectively, which are computed by the composite fields minus the 15-yr cold-season averaged fields.

\section{1) Composite UPPER-LEVEL JET STREAM}

Relative to the 15-yr cold-season averaged jet stream (Fig. 6a), the composite jet stream for NWP ECs with wind speed greater than $65 \mathrm{~m} \mathrm{~s}^{-1}$ at $300 \mathrm{hPa}$ extends more meridionally but less zonally (Fig. 11a). The highfrequency center of NWP ECs appears at the polarward side of the jet core. Figure 11b shows the jet-stream anomalies for NWP ECs at $300 \mathrm{hPa}$. The westerly anomalies occur near the jet core, which enhances the jet stream. The southwesterly anomalies with wind speed greater than $8 \mathrm{~m} \mathrm{~s}^{-1}$ appear to the east of the Japan Islands, which strengthens the southwesterly flow over the exit region of the jet stream. The high-frequency center of NWP ECs is located to the west of the southwesterly anomaly core.
The pattern of composite jet stream for NEP ECs shows distinct differences from that for NWP ECs. The jet stream for NEP ECs with wind speed greater than $60 \mathrm{~m} \mathrm{~s}^{-1}$ at $300 \mathrm{hPa}$ is more zonal (Fig. 11c). It extends to the northeastern Pacific and shows cyclonic curve over there. The high-frequency center of NEP ECs appears over the northwest of the cyclonic curve. Figure 11d shows the jet-stream anomalies for NEP ECs at $300 \mathrm{hPa}$. Strong southwesterly anomalies with wind speed greater than $10 \mathrm{~m} \mathrm{~s}^{-1}$ appear over the area of the cyclonic curve of the jet stream, which enhances the jet stream over the northeastern Pacific. The high-frequency center of NEP ECs is also located to the west of the southwesterly anomaly core.

The jet stream favoring rapid development for NWP and NEP ECs shows significant differences from that for the 15-yr cold-season average. The southwesterly anomalies appear to the east of the high-frequency centers of NWP and NEP ECs, which enhances the southwesterly flow of the jet stream there. The increasing southwesterly flow leads to stronger positive shear vorticity over their high-frequency center. In addition, Hoskins et al. (1985) indicated that upper-level cyclonic anomalies induced low-level cyclonic circulation, leading to an intense low-level cyclone through the interaction between the upper-level and low-level anomalies. The upper-level cyclonic anomalies that appear upstream of the high-frequency centers of NWP and NEP ECs favor the frequent occurrence of NWP and NEP ECs. The jet stream for NWP ECs differs from 

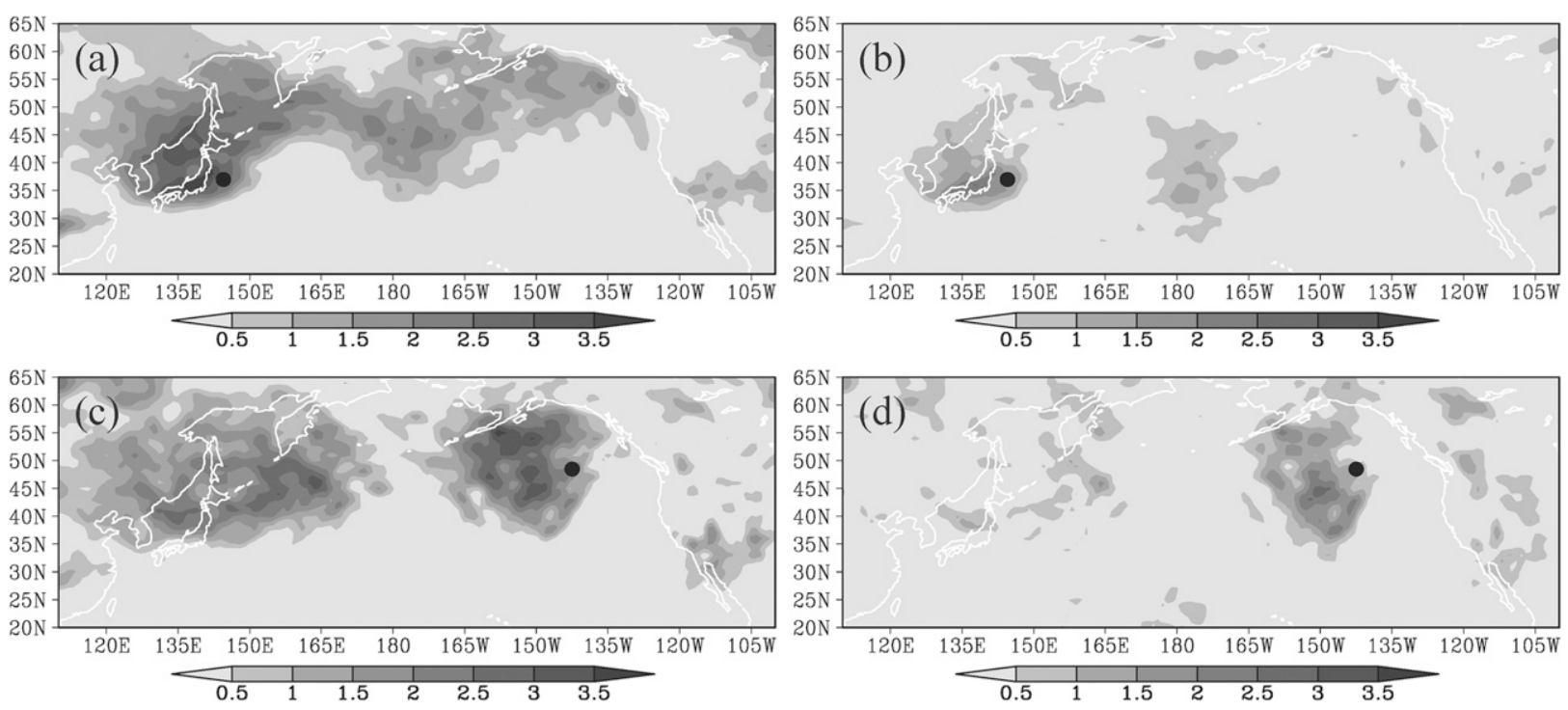

FIG. 12. As in Fig. 11, but for 500-hPa positive vorticity at $6 \mathrm{~h}$ before the maximum-rapid-deepening moment (shaded, with $0.5 \times 10^{-5} \mathrm{~s}^{-1}$ intervals) and the anomalies of positive vorticity (shaded, with $0.5 \times 10^{-5} \mathrm{~s}^{-1}$ intervals).

that for NEP ECs. The jet stream for NEP ECs is more zonal but weaker than that for NWP ECs, whereas the jet-stream anomalies for NEP ECs are stronger than those for NWP ECs to the east of their high-frequency centers.

\section{2) COMPOSITE MIDLEVEL POSITIVE VORTICITY}

Both the composite $500-\mathrm{hPa}$ vorticity at $6 \mathrm{~h}$ before the maximum-deepening-rate moment for NWP ECs and that for NEP ECs have major and minor regions with large positive vorticity (Figs. 12a,c). The pattern shows bimodal distribution. The major regions with large positive vorticity for NWP and NEP ECs appear upstream of their high-frequency centers, which are located off the eastern coast of the Japan Islands and over the northeastern Pacific, respectively. Figures $12 \mathrm{~b}$ and $12 \mathrm{~d}$ show the positive-vorticity anomalies for NWP and NEP ECs, respectively. The positive-vorticity anomalies for both NWP ECs and NEP ECs have single prominent areas, which are located near their major regions with large positive vorticity. The high-frequency centers of NWP and NEP ECs appear downstream of their respective prominent positive-vorticity-anomaly areas.

Although the patterns of composite 500-hPa vorticity for NWP and NEP ECs show bimodal distribution, their positive-vorticity-anomaly areas just appear over their major regions with large positive vorticity, which are also the positions of their high-frequency centers. Those results indicate that the positive-vorticity anomalies strengthen the positive vorticity over the high-frequency centers of NWP and NEP ECs and that the enhanced positive vorticity favors the frequent occurrence of
NWP and NEP ECs. The location and intensity of positive vorticity for NWP ECs differ from those for NEP ECs. In addition, the positive-vorticity anomalies for NEP ECs with more than $2.5 \times 10^{-5} \mathrm{~s}^{-1}$ over the northeastern Pacific are stronger than those for NWP ECs with more than $2.0 \times 10^{-5} \mathrm{~s}^{-1}$ off the eastern coast of the Japan Islands.

\section{Summary}

In this study, the characteristics of ECs over the northern Pacific during the cold season (October-April) over a 15-yr (2000-15) period are investigated by using FNL reanalysis data. According to the spatial distribution of MDPs and the temporal improvement of data, the definition of EC given by Sanders and Gyakum (1980) is modified to be a cyclone whose central SLP decrease normalized at $45^{\circ} \mathrm{N}$ is greater than $12 \mathrm{hPa}$ within $12 \mathrm{~h}$. These ECs are stratified into four categories of intensity according to their maximum deepening rates: weak (1.00-1.29 bergerons), moderate (1.30-1.69 bergerons), strong (1.70-2.29 bergerons), and super ( $\geq 2.30$ bergerons) ECs. In addition, ECs are further classified into five regions: JOS, NWP, WCP, ECP, and NEP ECs, on the basis of the five high-frequency centers of MDPs.

In total, 783 ECs are found over the northern Pacific. The occurrence frequency of ECs shows evident variations on the seasonal scale for the various regions over the northern Pacific. NWP ECs frequently occur in winter and early spring, WCP and ECP ECs frequently occur in winter, and JOS and NEP ECs mainly occur in 
TABLE A1. The information for strong (ST) and super (SU) ECs over the northern Pacific during the cold season (October-April) over a 15-yr (2000-15) period. Here, ID, PRE, lon, lat, MDR, NS, and IN indicate the identifier, the minimum central SLP, the longitude, the latitude, the maximum deepening rate, the classification number of the explosive-developing stage (see text), and the intensity (ST or SU) at the given time, respectively. The coding for the times is as follows: the first four digits are the year, the next two are the month, the next two are the day, and the final two are the hour (UTC) divided by 100. Thus, for example, the first entry 2004111418 corresponds to 1800 UTC 14 Nov 2004.

\begin{tabular}{|c|c|c|c|c|c|c|c|c|c|c|c|c|c|c|c|}
\hline \multirow[b]{2}{*}{ ID } & \multicolumn{4}{|c|}{ IFP } & \multicolumn{5}{|c|}{ MDP } & \multicolumn{4}{|c|}{ MCP } & \multirow[b]{2}{*}{ NS } & \multirow[b]{2}{*}{ IN } \\
\hline & Time & PRE & Lon & Lat & Time & PRE & Lon & at & & Time & PRE & Lon & Lat & & \\
\hline \multicolumn{16}{|c|}{ JOS ECs } \\
\hline 1 & 04111418 & 1002.8 & 133.0 & 49.0 & 2004111506 & 987.6 & 141.0 & 4 & 1 & 04111606 & 950.0 & 50.0 & & 1 & 列 \\
\hline 2 & 04112600 & 1009.8 & 129.7 & 41.0 & 004112606 & 992.6 & 133.0 & & & 04112718 & 950.2 & & & & ST \\
\hline 3 & 12040200 & 1006.2 & 112.6 & 31.2 & 012040300 & 988.2 & & & & 12040406 & 956.8 & & & & SU \\
\hline 4 & 013110918 & 1001.8 & 138.0 & 44.0 & & 973.6 & & & & & & & & & SU \\
\hline 5 & 2014121500 & 1023.6 & 120.0 & 39.3 & 014121600 & 1000.8 & 134.9 & 41.0 & & 1412 & 977.0 & 39.0 & 4.9 & & ST \\
\hline 6 & 1412 & 1019.8 & 121.8 & 38.6 & 014 & 976.0 & & 0 & 2.03 & 201412 & 957.0 & 145.4 & 53.3 & 1 & ST \\
\hline \multicolumn{16}{|c|}{ NWP ECs } \\
\hline 1 & 20 & 10 & 150.0 & & & 976.2 & 148.1 & 36 & & & & & & 2 & 1 \\
\hline 2 & 20011 & 1018.0 & 1361 & & & 968.2 & & & & & & & & & ST \\
\hline 3 & 2002112100 & 1010.8 & 147.5 & 43.6 & & 990.0 & & 48.0 & & & 965.6 & & & 1 & ST \\
\hline 4 & 200212 & 1009.6 & 133.4 & 37.0 & 6 & 970.8 & & 41.0 & & & & & & s & ST \\
\hline 5 & 200301 & 1012.0 & & & & 982.8 & & & & & & & & & ST \\
\hline 6 & 200302 & 1017.0 & & & & 986.4 & & & & & & & & & ST \\
\hline 7 & 2003 & 1008.4 & 7.5 & & & 4 & & & & & & & & & ST \\
\hline 8 & 2003 & 1013.4 & 1 & & & & & 37 & & & & & & & ST \\
\hline 9 & & & & & & & & & & & & & & & ST \\
\hline 10 & & 1007.2 & & & & & & & & & & & & 1 & ST \\
\hline 11 & 0 & 999.6 & & & & 6 & & & & & & & & & ST \\
\hline 12 & 0 & 999.2 & 0 & & & 0 & & & & & & & & & ST \\
\hline 13 & & 100 & & & & & & & & & & & & & ST \\
\hline 14 & & 1022.4 & & & & 0 & & & & & & & & & ST \\
\hline 15 & 8 & 09.0 & 9 & & & 6 & & 37 & & & & & & & ST \\
\hline 16 & 0 & 1009.6 & & & & & & & & & & & & & ST \\
\hline 17 & & & & & & & & & & & & & & & ST \\
\hline 18 & & 1012.8 & 1.2 & & & 977.4 & & 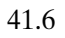 & & & & & & 1 & ST \\
\hline 19 & 8 & 13.8 & 4 & & & 8 & & 4 & & & & & & & SU \\
\hline 20 & 6 & 1009.6 & & & & & & & & & & & & & ST \\
\hline 21 & & & & & & & & & & & & & & & ST \\
\hline 22 & 8 & 1020.6 & 7 & & & 968.4 & & 50 & & & & & 52.0 & 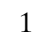 & ST \\
\hline 23 & 2008020206 & 1008.6 & 128.0 & & & 987.2 & & 35.0 & & & .2 & & & 1 & ST \\
\hline 24 & & & & & & & & & & & & & & & ST \\
\hline 25 & & & & & & & & & & & & & & 1 & SU \\
\hline 26 & & 1006.8 & & & & & & & & & & & & 1 & SU \\
\hline 27 & & 05.8 & & & & & & & & & & & & 1 & ST \\
\hline 28 & & & & & & & & & & & & & & 1 & ST \\
\hline 29 & 6 & 6 & 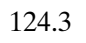 & 3 & & 4 & & 9 & & & & & 9 & 1 & ST \\
\hline 30 & & 1011.2 & & & & & & & & & & & & 2 & ST \\
\hline 31 & 600 & & & & & & & & & & & & & 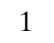 & ST \\
\hline 32 & & & & & & & & & & & & & & 2 & ST \\
\hline 33 & 18 & 1009.2 & 9 & & & 977.2 & & 41.9 & & & 946.6 & 0 & 50.0 & 1 & ST \\
\hline 34 & 2010013118 & 1011.8 & & & & & & 36.0 & & & & & & 1 & ST \\
\hline 35 & & & & & & & & & & & & & & 1 & ST \\
\hline 36 & & & & & & & & & & & & & & 1 & ST \\
\hline 37 & 2010102418 & 1003.6 & 140.9 & 44 & & 964.2 & & 54.0 & & 06 & 948.4 & 2.0 & 59.0 & 1 & ST \\
\hline 38 & 2011011506 & 1003.4 & & & & 960.0 & & 40.5 & & & 934.2 & & 44.0 & 1 & SU \\
\hline 39 & & & & & & & & & & & & & 51.0 & 1 & ST \\
\hline 40 & 2011031400 & 1013.4 & 102.4 & 29.0 & & & & 41.1 & & & 936.6 & & 48.0 & 1 & ST \\
\hline 41 & 2012010106 & 1014.4 & 134.3 & 27.9 & & 984.8 & & 38.0 & & & 960.2 & 153.0 & 43.0 & 1 & ST \\
\hline 42 & 2012011012 & 1016.8 & 144.0 & 33. & 2012011200 & 973.2 & 163.0 & 45.0 & 2. & 2012011218 & 945.0 & 162.0 & 51.0 & 1 & ST \\
\hline 43 & 20120 & 1009.8 & 142.1 & 35 . & & & & 40.0 & & & & & 43.0 & 1 & ST \\
\hline 44 & 2012113006 & 1009.0 & 139.9 & 31.0 & 2012120112 & 976.8 & 155.1 & 45.0 & 2.02 & 2012120200 & 961.4 & 154.0 & 50.0 & 1 & ST \\
\hline
\end{tabular}


TABLE A1. (Continued)

\begin{tabular}{|c|c|c|c|c|c|c|c|c|c|c|c|c|c|c|c|}
\hline \multirow[b]{2}{*}{ ID } & \multicolumn{4}{|c|}{ IFP } & \multicolumn{5}{|c|}{ MDP } & \multicolumn{4}{|c|}{ MCP } & \multirow[b]{2}{*}{ NS } & \multirow[b]{2}{*}{ IN } \\
\hline & Time & PRE & Lon & Lat & Time & $\mathrm{RE}$ & Lon & Lat & $\mathrm{DR}$ & Time & PRE & Lon & Lat & & \\
\hline $4 J$ & 12 & & 8.1 & 9 & & & & & & & & & & 1 & \\
\hline 46 & 13020318 & 18.2 & & & 00 & 9.8 & & & & & & 0 & & & $T$ \\
\hline 47 & 13021200 & 17.8 & 26.0 & 7.0 & 13021306 & 1.4 & & & & & & 172.0 & & & $\mathrm{TT}$ \\
\hline 48 & 13021418 & 1012.8 & 30.8 & 30.1 & 1302 & & & & & & & & & & $\mathrm{TT}$ \\
\hline 49 & 13031918 & 1007.0 & 23.0 & 10 & & & & & & & & & & & ST \\
\hline 50 & 13033112 & 1011.4 & & 37.0 & 6 & 1.0 & & & & & & & & 1 & ST \\
\hline 51 & 13110318 & 10.8 & & 0.1 & 06 & 9.2 & & & & & & & & & ST \\
\hline 52 & 13122606 & 10.4 & & & 8 & & & & & & & & & & ST \\
\hline 53 & 014110612 & 93.6 & 43.0 & & 2 & 2.2 & & & & & & & & & SU \\
\hline 54 & & 008.0 & & 60 & & 4.6 & & & & & & & & & ST \\
\hline 55 & 2 & & & 35.0 & & & & & & & & & & & ST \\
\hline 56 & 14 & 5 & & & & & & & & & & & & & $\mathrm{U}$ \\
\hline 57 & & & & & & & & & & & & & & & $\mathrm{ST}$ \\
\hline 58 & 12 & 0074 & 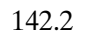 & 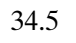 & & & & & & & & 166.1 & & 1 & ST \\
\hline \multicolumn{16}{|c|}{ WCP ECs } \\
\hline 1 & & & & & & 1.0 & & & & & & & & & ST \\
\hline 2 & & & & & & & & & & & & & & & ST \\
\hline 3 & 2001 & 2 & 6 & 0 & & & & & & & & & & & ST \\
\hline 4 & 200 & 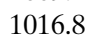 & 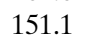 & 34.7 & & & & & & & & & & & $\mathrm{ST}$ \\
\hline 5 & & & & & & & & & & & & & & & ST \\
\hline 6 & 200 & & 0 & 52 & & & & & & & & & & & ST \\
\hline 7 & 00 & 3 & 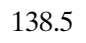 & 29.6 & & & & & & & & & & & ST \\
\hline 8 & 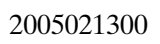 & 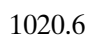 & & 33.0 & & 0 & & & & & & & & & $\mathrm{~T}$ \\
\hline 9 & & & & & & & & & & & & & & & \\
\hline 10 & & & & & & & & & & & & & & & $\mathrm{~T}$ \\
\hline 11 & 8 & 2 & 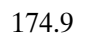 & 25.0 & & 2 & & & & & & & & & ST \\
\hline 12 & 6 & 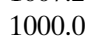 & & & & & & & & & & & & & ST \\
\hline 13 & & & & & & & & & & & & & & & $\mathrm{~T}$ \\
\hline 14 & & & & 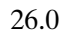 & & & & & & & & & & & ST \\
\hline 15 & 6 & 5 & ) & 2. & & 5.8 & 1 & & & & 4 & 0 & & & SU \\
\hline 16 & & & & & & & & & & & & & & & SU \\
\hline 17 & & 2 & & 34. & & .2 & & & & & & & & 1 & ST \\
\hline 18 & & & & 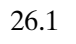 & & & & & & & & & & 2 & ST \\
\hline 19 & 2 & 5 & & & & & & & & & & & & 1 & ST \\
\hline 20 & & & & & & & & & & & & & & & $\mathrm{ST}$ \\
\hline 21 & 6 & . & & 34.5 & & & & & & & & & & 1 & ST \\
\hline 22 & & & & 30 & & & & & & & & & & 1 & ST \\
\hline 23 & & & & & & & & & & & & & & 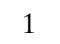 & ST \\
\hline 24 & & & & & & & & & & & & & & & SU \\
\hline 25 & 6 & ( & 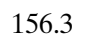 & 31.8 & & & & & & & & & & 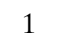 & ST \\
\hline 26 & & & & & & & & & & & & & & 1 & ST \\
\hline 27 & & & & & & & & & & & & & & & ST \\
\hline 28 & & & & & & & & & & & & & & & ST \\
\hline 29 & 2014121600 & 998.8 & 170.0 & 39.0 & 2014121612 & 4.2 & 181.0 & 42.0 & 1.8 & 2014121712 & 958.8 & 198.0 & 47.9 & 1 & ST \\
\hline \multicolumn{16}{|c|}{ ECP ECs } \\
\hline 1 & & & & & & & & & & & & & & & \\
\hline 2 & & & & & & & & & & & & & & & ST \\
\hline 3 & 2002102606 & 1000.6 & 183.0 & 40.0 & & 4.6 & 192.1 & 42.0 & & & 961.6 & 201.1 & 44.9 & 1 & ST \\
\hline 4 & 2002112612 & & & & & & & & & & & 204.0 & 44 & 1 & ST \\
\hline 5 & & & & & & & & & & & & & & & $\mathrm{TT}$ \\
\hline 6 & & & & & & & & & & & & & & & ST \\
\hline 7 & 20051 & 1001.4 & 162.0 & 32.0 & 12 & 982.0 & 191.1 & 43.0 & & 400 & 963.6 & 198.1 & 48.2 & 1 & ST \\
\hline 8 & 2007112412 & & $100 \Omega$ & 40.9 & 00 & 982.0 & 201.6 & 44.0 & & & 961.8 & 208.1 & & 1 & ST \\
\hline 9 & 20071 & & & 29.0 & & & & & & & & & & & SU \\
\hline 10 & 2009100812 & 1000.6 & 189.1 & 35.0 & 2009100900 & 983.4 & 200.0 & 40.0 & 2.08 & 2009100918 & 967.0 & 204.0 & 48.9 & 1 & $\mathrm{~T}$ \\
\hline 11 & 2009112100 & 1014.0 & 145.1 & 35.1 & 2009112300 & 991.0 & & 40.1 & 1.75 & 2009112400 & 961.2 & 201.0 & 44.0 & 1 & ST \\
\hline 12 & 2010022300 & 1010.8 & 131.9 & 22.4 & 2010022606 & 975.6 & 186.0 & 39.0 & 2.20 & 2010022700 & 951.0 & 190.0 & 45.0 & 2 & (9m \\
\hline
\end{tabular}


TABLE A1. (Continued)

\begin{tabular}{|c|c|c|c|c|c|c|c|c|c|c|c|c|c|c|c|}
\hline \multirow[b]{2}{*}{ ID } & \multicolumn{4}{|c|}{ IFP } & \multicolumn{5}{|c|}{ MDP } & \multicolumn{4}{|c|}{ MCP } & \multirow[b]{2}{*}{ NS } & \multirow[b]{2}{*}{ IN } \\
\hline & Time & PRE & Lon & Lat & Time & PRE & Lon & Lat & MDR & Time & PRE & Lon & Lat & & \\
\hline 13 & 10102806 & 06.0 & 138.7 & 9 & 10103 & 64.0 & 1.0 & 49.0 & & 1010 & 39.4 & 98.0 & 0.0 & 1 & SU \\
\hline 14 & 06 & 1010.6 & 130.0 & & 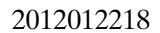 & & & & & 6 & 2.8 & & & & ST \\
\hline 15 & 12020906 & 997.0 & 164.1 & 37.9 & 012021006 & 964.0 & 189.0 & 44.0 & & 12021100 & 950.2 & 198.9 & 50.9 & 1 & ST \\
\hline 16 & 12122900 & 982.8 & 193.0 & 38.0 & 2012122906 & 968.0 & 198.0 & 40.1 & 2.07 & 12123006 & 951.0 & 206.4 & 52.5 & 1 & ST \\
\hline 17 & 4011600 & 977.8 & 199.0 & & & & 0 & 41.1 & & & 53.8 & 1.0 & 8.1 & & ST \\
\hline 18 & & 1008.8 & 151.9 & 36.9 & & 7.8 & & 43. & & 12 & 953.6 & 202.4 & 52.0 & 1 & ST \\
\hline \multicolumn{16}{|c|}{ NEP ECs } \\
\hline 1 & 00 & 1012.4 & 184.0 & 36.0 & 2 & 988.4 & 212.9 & 50.0 & & 0 & 961.2 & 223.9 & 50.0 & 1 & ST \\
\hline 2 & 20011 & 1011.4 & 212.0 & 42.0 & 20011 & 987.6 & & 49.0 & & 12 & 972.4 & 3.0 & 54.0 & 1 & ST \\
\hline 3 & 2004100518 & 1015.2 & 177.7 & 43.9 & 200410 & 980.2 & 214.0 & 46.0 & 2. & 18 & 964.8 & 219.0 & 49.0 & 1 & ST \\
\hline 4 & 2006010318 & 999.0 & 208.0 & 32.0 & 2006010400 & 983.2 & 213.1 & 34.0 & & 006010 & 964.4 & 218.0 & 39.1 & 1 & SU \\
\hline 5 & 2006122306 & 995.2 & 201.3 & 40.5 & 2006122400 & 961.6 & 212.0 & 46.9 & & 12 & 945.0 & 214.0 & 49.0 & 1 & ST \\
\hline 6 & 2006122806 & 993.8 & 208.8 & 40.9 & 20061 & 972.8 & .0 & 47.0 & 2 & 18 & 950.4 & 215.0 & 57.0 & 1 & ST \\
\hline 7 & 2007100712 & 1014.6 & 189.2 & 44.0 & 2007100818 & 984.0 & 222.1 & 41.0 & & 2007100912 & 965.4 & 227.0 & 46.0 & 1 & SU \\
\hline 8 & 2008022300 & & & & & 977.8 & & 37.0 & & & 972.8 & 223.2 & 37.4 & 1 & ST \\
\hline 9 & 2010021012 & 998.4 & 159.0 & 45.0 & 20100 & 971.2 & 205.6 & 41.0 & 2.1 & 2010 & 951.2 & 213.5 & 45.0 & 1 & ST \\
\hline 10 & 2010111618 & 1018.6 & 217.0 & 48.0 & 2010111700 & 1006.6 & 222.8 & 49.1 & 2.0 & 2010111712 & 982.8 & 228.0 & 52.0 & 1 & ST \\
\hline 11 & 2012033012 & 1006.0 & 171.8 & 31.1 & 2012040112 & 984.4 & 210.0 & 44.0 & 1.97 & 2012040212 & 958.6 & 221.0 & 52.0 & 1 & ST \\
\hline 12 & & & & 34.0 & & & & 36.0 & & & 971.6 & & 36.9 & 1 & ST \\
\hline 13 & 2015013006 & 996.6 & 207.0 & 34.2 & 2015013018 & 977.6 & 208.5 & 42.0 & 2.11 & 2015013112 & 954.0 & 205.0 & 45.1 & 1 & ST \\
\hline
\end{tabular}

autumn and early spring. The occurrence frequency, averaged maximum deepening rate, and developing and explosive-developing lifetimes of ECs decrease eastward over the northern Pacific, excluding JOS ECs. The moving tracks of JOS and NWP ECs are usually in the northeastward direction. Those of WCP and ECP ECs are generally in the eastward direction in early stages, and they turn to the northeastward direction in later stages. NEP ECs travel along the two directions as mentioned above depending on their initial formation positions.

ECs predominantly appear at the poleward side of the upper-level jet stream, within and at the equatorward side of midlevel positive vorticity, and over strong lowlevel baroclinicity. Moreover, these large-scale environments decrease eastward over the northern Pacific, which results in the characteristics of the eastwarddecreasing trend of the occurrence frequency, averaged maximum deepening rate, and developing and explosive-developing lifetimes of ECs in the cold season. The occurrence frequency and spatial distribution of ECs are highly correlated with the intensity and position of the upper-level jet stream, respectively, on the seasonal scale and also with those of midlevel positive vorticity and low-level baroclinicity. A warm ocean surface associated with abundant sensible and latent heat fluxes also favors rapid intensification of ECs, this process is more important over the northwestern Pacific and leads to more frequent activities of ECs over the Kuroshio/Kuroshio Extension. The composite analysis indicates that the large-scale atmospheric environment for NWP and NEP ECs shows significant differences from that for the 15-yr cold-season average. The southwesterly anomalies of upper-level stream and positive anomalies of midlevel vorticity favor the frequent occurrence of NWP and NEP ECs.

We have discussed the large-scale atmospheric and oceanic environments, such as the upper-level jet stream, midlevel positive vorticity, low-level baroclinicity, SST, and SST gradient, in relation to the occurrence frequency and spatial distribution of ECs. In addition, the diabatic process was also taken as an important factor favoring the rapid development of ECs (Ahmadi-Givi et al. 2004; Kuwano-Yoshida and Asuma 2008; Kuwano-Yoshida and Enomoto 2013; Hirata et al. 2015), and we have tried to use precipitable water, specific humidity, moisture flux, and moisture flux convergence to investigate the influence of the diabatic process on the occurrence frequency and spatial distribution of ECs on the seasonal scale (not shown). These meteorological variables showed insignificant correlation with the occurrence frequency and spatial distribution of ECs on the seasonal scale. Other meteorological variables or methods are still needed to examine the diabatic process. Moreover, composite analyses and case studies are required for further understanding the development mechanisms and detailed structures of various types of ECs. The diabatic process can probably be investigated successfully in such future work. 

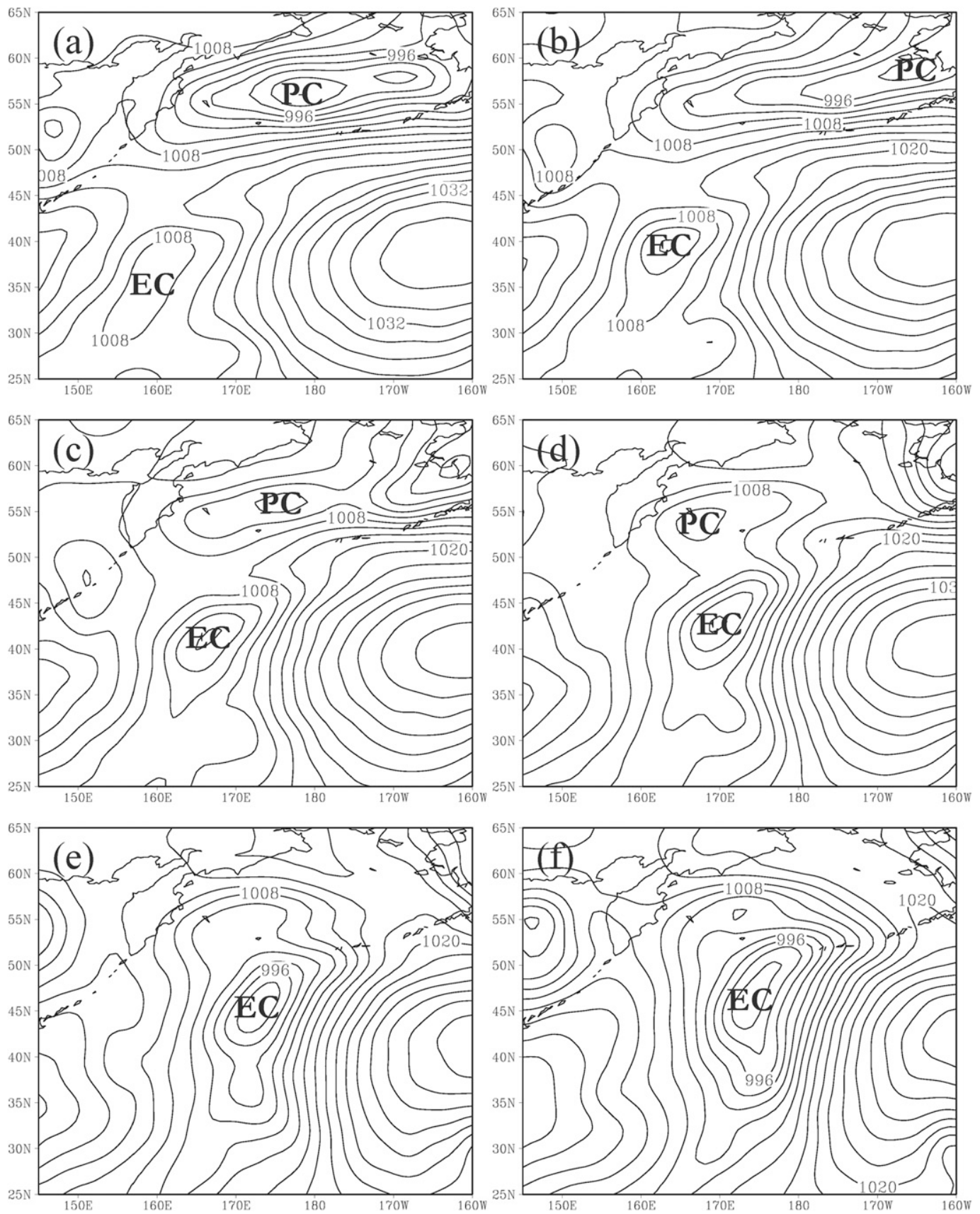

FIG. A1. The progression of the SLP pattern (3-hPa contours) for a merged EC: (a) 1800 UTC 4, (b) 0000 UTC 5 , (c) 0600 UTC 5, (d) 1200 UTC 5, (e) 1800 UTC 5, and (f) 0000 UTC 6 Apr 2011. The label PC indicates the parent cyclone.

Acknowledgments. The authors express their thanks to the National Natural Science Foundation of China (NSFC) for financial support (Grants 41275049 and 41775042). All authors express their sincere thanks to Prof. Shangping Xie at the Scripps Institution of Oceanography, University of California; Dr. Huaji Pang at the Qingdao Meteorological Bureau; Dr. Pengyuan Li at the Department of Marine Meteorology, Ocean University of China; and Prof. Yanluan Lin in the Ministry of Education Key Laboratory for Earth System Modeling, Department of Earth System Science, and Joint Center for Global Change Studies of Tsinghua University, China, for their helpful discussions. Special thanks are given to NCEP for providing FNL data and to 

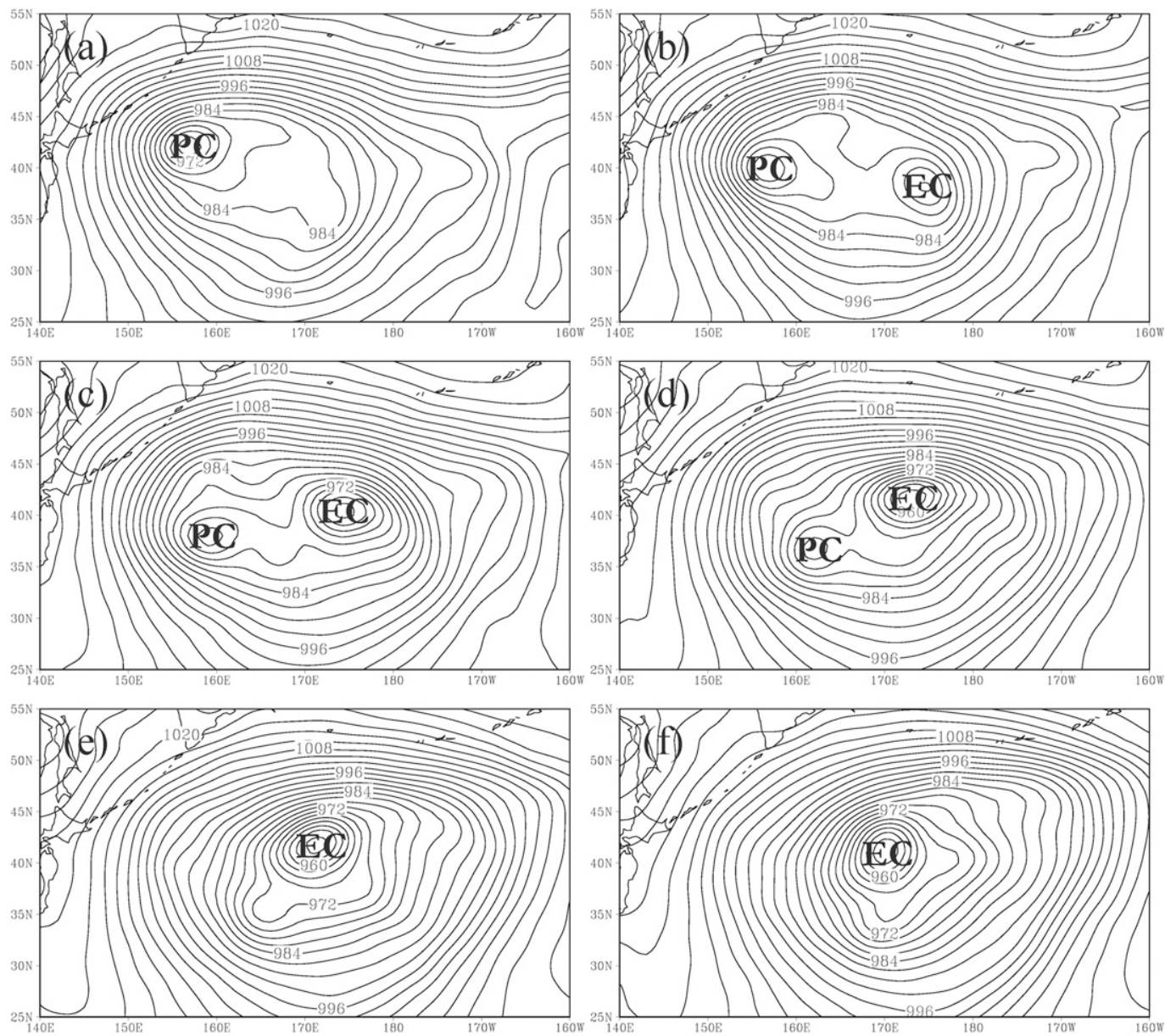

FIG. A2. As in Fig. A1, but for a splitting EC: (a) 1200 UTC16, (b) 1800 UTC 16, (c) 0000 UTC 17, (d) 0600 UTC17, (e) 1200 UTC 17, and (f) 1800 UTC 17 Dec 2013.

NCDC for providing AVHRR infrared satellite SST data. Jingwu Liu was supported by NSFC (Grants 41505003) and the Shandong Province Science Foundation of China (2014ZRE29087).

\section{APPENDIX}

\section{Detailed Information and Examples}

Detailed information about strong and "super" ECs over the northern Pacific during the cold season (OctoberApril) over a 15-yr (2000-15) period is given in Table A1. The SLP patterns with time for examples of merged and splitting ECs are shown in Figs. A1 and A2, respectively.

\section{REFERENCES}

Ahmadi-Givi, F., G. C. Graig, and R. S. Plant, 2004: The dynamics of a midlatitude cyclone with very strong latent-heat release. Quart. J. Roy. Meteor. Soc., 130, 295-323, https://doi.org/ 10.1256/qj.02.226.
Allen, J., A. Pezza, and M. Black, 2010: Explosive cyclogenesis: A global climatology comparing multiple reanalyses. J. Climate, 23, 6468-6484, https://doi.org/10.1175/2010JCLI3437.1.

Anthes, R. A., Y.-H. Kuo, and J. R. Gyakum, 1983: Numerical simulations of a case of explosive marine cyclogenesis. Mon. Wea. Rev., 111, 1174-1188, https://doi.org/10.1175/1520-0493(1983)111<1174: $\mathrm{NSOACO}>2.0 . \mathrm{CO} ; 2$.

Azad, R., and A. Sorteberg, 2014: The vorticity budgets of North Atlantic winter extratropical cyclone life cycles in MERRA reanalysis. Part I: Development phase. J. Atmos. Sci., 71, 3109-3128, https://doi.org/10.1175/JAS-D-13-0267.1.

Booth, J. F., L. Thompson, J. Patoux, and K. A. Kelly, 2012: Sensitivity of midlatitude storm intensification to perturbations in the sea surface temperature near the Gulf Stream. Mon. Wea. Rev., 140, 1241-1256, https://doi.org/10.1175/MWR-D-11-00195.1.

Bosart, L. F., 1981: The Presidents' Day snowstorm of 18-19 February 1979: A subsynoptic-scale event. Mon. Wea. Rev., 109, 1542-1566, https://doi.org/10.1175/1520-0493(1981)109<1542: TPDSOF $>2.0 . \mathrm{CO} ; 2$.

— , and S. C. Lin, 1984: A diagnostic analysis of the Presidents' Day storm of February 1979. Mon. Wea. Rev., 112, 2148-2177, https:// doi.org/10.1175/1520-0493(1984)112<2148:ADAOTP>2.0.CO;2.

Bullock, T. A., and J. R. Gyakum, 1993: A diagnostic study of cyclogenesis in the western North Pacific Ocean. Mon. Wea. Rev., 
121, 65-75, https://doi.org/10.1175/1520-0493(1993)121<0065: ADSOCI $>2.0 . \mathrm{CO} ; 2$.

Cammas, J.-P., and D. Ramond, 1989: Analysis and diagnosis of the composite of ageostrophic circulations in jet-front systems. Mon. Wea. Rev., 117, 2447-2462, https://doi.org/10.1175/ 1520-0493(1989)117<2447:AADOTC >2.0.CO;2.

Chen, S.-J., Y.-H. Kuo, P.-Z. Zhang, and Q.-F. Bai, 1991: Synoptic climatology of cyclogenesis over East Asia, 19581987. Mon. Wea. Rev., 119, 1407-1418, https://doi.org/ 10.1175/1520-0493(1991)119<1407:SCOCOE > 2.0.CO;2.

,,,--- and -1992 : Climatology of explosive cyclones off the East Asian coast. Mon. Wea. Rev., 120, 3029-3035, https:// doi.org/10.1175/1520-0493(1992)120<3029:COECOT>2.0.CO;2.

Chen, T.-C., C.-B. Chang, and D. J. Perkey, 1983: Numerical study of an AMTEX '75 oceanic cyclone. Mon. Wea. Rev., 111, 1818-1829, https://doi.org/10.1175/1520-0493(1983)111<1818: NSOAAO $>2.0 . \mathrm{CO} ; 2$.

,-- , and $\longrightarrow$ 1985: Synoptic study of a medium-scale oceanic cyclone during AMTEX '75. Mon. Wea. Rev., 113, 349-361, https://doi.org/10.1175/1520-0493(1985)113<0349: SSOAMS $>2.0 . \mathrm{CO} ; 2$.

Cressman, G. P., 1959: An operational objective analysis system. Mon. Wea. Rev., 87, 367-375, https://doi.org/10.1175/ 1520-0493(1959)087<0367:AOOAS > 2.0.CO;2.

Danielson, R. E., J. R. Gyakum, and D. N. Straub, 2006a: A case study of downstream baroclinic development over the North Pacific Ocean. Part I: Dynamical impacts. Mon. Wea. Rev. 134, 1534-1548, https://doi.org/10.1175/MWR3172.1.

$\longrightarrow, \ldots$, and _ 2006b: A case study of downstream baroclinic development over the North Pacific Ocean. Part II: Diagnoses of eddy energy and wave activity. Mon. Wea. Rev., 134, 15491567, https://doi.org/10.1175/MWR3173.1.

Davis, C. A., and K. A. Emanuel, 1988: Observational evidence for the influence of surface heat fluxes on rapid maritime cyclogenesis. Mon. Wea. Rev., 116, 2649-2659, https://doi.org/ 10.1175/1520-0493(1988)116<2649:OEFTIO > 2.0.CO;2.

Emanuel, K. A., M. Fantini, and A. J. Thorpe, 1987: Baroclinic instability in an environment of small stability to slantwise moist convection. Part I: Two-dimensional models. J. Atmos. Sci., 44 1559-1573, https://doi.org/10.1175/1520-0469(1987)044<1559: BIIAEO $>2.0 . \mathrm{CO} ; 2$

Gall, R., 1976: The effects of released latent heat in growing baroclinic waves. J. Atmos. Sci., 33, 1686-1701, https://doi.org/ 10.1175/1520-0469(1976)033<1686:TEORLH>2.0.CO;2.

Gyakum, J. R., 1983a: On the evolution of the $Q E$ II storm. I: Synoptic aspects. Mon. Wea. Rev., 111, 1137-1155, https://doi.org/ 10.1175/1520-0493(1983)111<1137:OTEOTI > 2.0.CO;2.

_ 1983b: On the evolution of the $Q E I I$ storm. II: Dynamic and thermodynamic structure. Mon. Wea. Rev., 111, 1156-1173, https:// doi.org/10.1175/1520-0493(1983)111<1156:OTEOTI>2.0.CO;2.

- 1991: Meteorological precursors to the explosive intensification of the QE II storm. Mon. Wea. Rev., 119, 1105-1131, https://doi.org/ 10.1175/1520-0493(1991)119<1105:MPTTEI > 2.0.CO;2.

— cursors to ordinary and explosive cyclogenesis in the western North Pacific. Mon. Wea. Rev., 128, 851-863, https://doi.org/ 10.1175/1520-0493(2000)128<0851:AOMPTO > 2.0.CO;2.

_ _ J. R. Anderson, R. H. Grumm, and E. L. Gruner, 1989: North Pacific cold-season surface cyclone activity: 19751983. Mon. Wea. Rev., 117, 1141-1155, https://doi.org/10.1175/ 1520-0493(1989)117<1141:NPCSSC $>2.0 . C O ; 2$.

Hirata, H., R. Kawamura, M. Kato, and T. Shinoda, 2015: Influential role of moisture supply from the Kuroshio/Kuroshio
Extension in the rapid development of an extratropical cyclone. Mon. Wea. Rev., 143, 4126-4144, https://doi.org/ 10.1175/MWR-D-15-0016.1.

Hirschberg, P. A., and J. M. Fritsch, 1991: Tropopause undulations and the development of extratropical cyclones. Part I: Overview and observations from a cyclone event. Mon. Wea. Rev., 119, 496-550, https://doi.org/10.1175/1520-0493(1991)119<0496: TUATDO $>2.0 . \mathrm{CO} ; 2$.

Hoskins, B. J., and P. J. Valdes, 1990: On the existence of stormtracks. J. Atmos. Sci., 47, 1854-1864, https://doi.org/10.1175/ 1520-0469(1990)047<1854:OTEOST>2.0.CO;2.

— M. E. McIntyre, and A. W. Robertson, 1985: On the use and significance of isentropic potential vorticity maps. Quart. J. Roy. Meteor. Soc., 111, 877-946, https://doi.org/10.1002/qj.49711147002.

Hotta, D., and H. Nakamura, 2011: On the significance of the sensible heat supply from the ocean in the maintenance of the mean baroclinicity along storm tracks. J. Climate, 24, 33773401, https://doi.org/10.1175/2010JCLI3910.1.

Iizuka, S., M. Shiota, R. Kawamura, and H. Hatsushika, 2013: Influence of the monsoon variability and sea surface temperature front on the explosive cyclone activity in the vicinity of Japan during northern winter. SOLA, 9, 1-4, http://doi.org/ 10.2151/sola.2013-001.

Iwao, K., M. Inatsu, and M. Kimoto, 2012: Recent changes in explosively developing extratropical cyclones over the winter northwestern Pacific. J. Climate, 25, 7282-7296, https://doi.org/ 10.1175/JCLI-D-11-00373.1.

Kelly, K. A., R. J. Small, R. M. Samelson, B. Qiu, T. M. Joyce, Y.-O. Kwon, and M. F. Cronin, 2010: Western boundary currents and frontal air-sea interaction: Gulf Stream and Kuroshio Extension. J. Climate, 23, 5644-5667, https://doi.org/ 10.1175/2010JCLI3346.1.

Keyser, D., and M. A. Shapiro, 1986: A review of the structure and dynamics of upper-level frontal zones. Mon. Wea. Rev., 114, 452-499, https://doi.org/10.1175/1520-0493(1986)114<0452: AROTSA $>2.0 . \mathrm{CO} ; 2$.

Kuo, Y.-H., R. J. Reed, and S. Low-Nam, 1991a: Effects of surface energy fluxes during the early development and rapid intensification stages of seven explosive cyclones in the western Atlantic. Mon. Wea. Rev., 119, 457-476, https://doi.org/ 10.1175/1520-0493(1991)119<0457:EOSEFD>2.0.CO;2.

_ M. A. Shapiro, and E. G. Donall, 1991b: The interaction between baroclinic and diabatic processes in a numerical simulation of rapidly intensifying extratropical marine cyclone. Mon. Wea. Rev., 119, 368-384, https://doi.org/10.1175/ 1520-0493(1991)119<0368:TIBBAD > 2.0.CO;2.

Kuwano-Yoshida, A., and Y. Asuma, 2008: Numerical study of explosively developing extratropical cyclones in the northwestern Pacific region. Mon. Wea. Rev., 136, 712-740, https:// doi.org/10.1175/2007MWR2111.1.

, and T. Enomoto, 2013: Predictability of explosive cyclogenesis over the northwestern Pacific region using ensemble reanalysis. Mon. Wea. Rev., 141, 3769-3785, https://doi.org/ 10.1175/MWR-D-12-00161.1.

Kwon, Y.-O., M. A. Alexander, N. A. Bond, C. Frankignoul, H. Nakamura, B. Qiu, and L. Thompson, 2010: Role of the Gulf Stream and Kuroshio-Oyashio systems in large-scale atmosphere-ocean interaction: A review. J. Climate, 23, 32493281, https://doi.org/10.1175/2010JCLI3343.1.

Lim, E.-P., and I. Simmonds, 2002: Explosive cyclone development in the Southern Hemisphere and a comparison with Northern Hemisphere events. Mon. Wea. Rev., 130, 2188-2209, https:// doi.org/10.1175/1520-0493(2002)130<2188:ECDITS>2.0.CO;2. 
Lupo, A. R., P. J. Smith, and P. Zwack, 1992: A diagnosis of the explosive development of two extratropical cyclones. Mon. Wea. Rev., 120, 1490-1523, https://doi.org/10.1175/1520-0493(1992)120<1490: ADOTED $>2.0 . \mathrm{CO} ; 2$.

Macdonald, B. C., and E. R. Reiter, 1988: Explosive cyclogenesis over the eastern United States. Mon. Wea. Rev., 116, 15681586, https://doi.org/10.1175/1520-0493(1988)116<1568: ECOTEU $>2.0 . \mathrm{CO} ; 2$.

Manobianco, J., 1989: Explosive east coast cyclogenesis over the west-central North Atlantic Ocean: A composite study derived from ECMWF operational analyses. Mon. Wea. Rev., 117, 2365-2383, https://doi.org/10.1175/1520-0493(1989)117<2365: EECCOT>2.0.CO;2.

Mullen, S. L., and D. P. Baumhefner, 1988: Sensitivity of numerical simulations of explosive oceanic cyclogenesis to changes in physical parameterizations. Mon. Wea. Rev., 116, 2289-2329, https://doi.org/10.1175/1520-0493(1988)116<2289: SONSOE $>2.0 . \mathrm{CO} ; 2$.

Murty, T., G. McBean, and B. McKee, 1983: Explosive cyclogenesis over the northeast Pacific Ocean. Mon. Wea. Rev., 111, 1131-1135, https://doi.org/10.1175/1520-0493(1983)111<1131: ECOTNP $>2.0 . \mathrm{CO} ; 2$.

Nakamura, H., 1992: Midwinter suppression of baroclinic wave activity in the Pacific. J. Atmos. Sci., 49, 1629-1642, https://doi.org/ 10.1175/1520-0469(1992)049<1629:MSOBWA > 2.0.CO;2.

- 1993: Horizontal divergence associated with zonally isolated jet streams. J. Atmos. Sci., 50, 2310-2313, https://doi.org/ 10.1175/1520-0469(1993)050<2310:HDAWZI >2.0.CO;2.

Neiman, P. J., and M. A. Shapiro, 1993: The life cycle of an extratropical marine cyclone. Part I: Frontal-cyclone evolution and thermodynamic air-sea interaction. Mon. Wea. Rev., 121, 2153-2176, https://doi.org/10.1175/1520-0493(1993)121<2153: TLCOAE $>2.0 . \mathrm{CO} ; 2$.

Neu, U., and Coauthors, 2013: IMILAST: A community effort to intercompare extratropical cyclone detection and tracking algorithms. Bull. Amer. Meteor. Soc., 94, 529-547, https://doi.org/ 10.1175/BAMS-D-11-00154.1.

Nuss, W. A., and S. I. Kamikawa, 1990: Dynamics and boundary layer processes in two Asian cyclones. Mon. Wea. Rev., 118, 755-771, https://doi.org/10.1175/1520-0493(1990)118<0755: DABLPI $>2.0 . \mathrm{CO} ; 2$.

Reader, M. C., and G. W. K. Moore, 1995: Stratospheretroposphere interactions associated with a case of explosive cyclogenesis in the Labrador Sea. Tellus, 47A, 849-863, https:// doi.org/10.3402/tellusa.v47i5.11579.

Reed, R. J., G. A. Grall, and Y.-H. Kuo, 1993: The ERICA IOP 5 storm. Part II: Sensitivity tests and further diagnosis based on model output. Mon. Wea. Rev., 121, 1595-1612, https://doi.org/ 10.1175/1520-0493(1993)121<1595:TEISPI>2.0.CO;2.

Rice, R. B., 1979: Tracking a killer storm. Sail, October issue, 106-107.

Roebber, P. J., 1984: Statistical analysis and updated climatology of explosive cyclones. Mon. Wea. Rev., 112, 1577-1589, https://doi.org/ 10.1175/1520-0493(1984)112<1577:SAAUCO > 2.0.CO;2.

Rogers, E., and L. F. Bosart, 1986: An investigation of explosively deepening oceanic cyclones. Mon. Wea. Rev., 114, 702-718, https:// doi.org/10.1175/1520-0493(1986)114<0702:AIOEDO>2.0.CO;2.

Sanders, F., 1986: Explosive cyclogenesis in the west-central North Atlantic Ocean, 1981-84. Part I: Composite structure and mean behavior. Mon. Wea. Rev., 114, 1781-1794, https://doi.org/ 10.1175/1520-0493(1986)114<1781:ECITWC>2.0.CO;2.
_ the "bomb." Mon. Wea. Rev., 108, 1589-1606, https://doi.org/ 10.1175/1520-0493(1980)108<1589:SDCOT>2.0.CO;2.

— , and C. A. Davis, 1988: Patterns of thickness anomaly for explosive cyclogenesis over the west-central North Atlantic Ocean. Mon. Wea. Rev., 116, 2725-2730, https://doi.org/ 10.1175/1520-0493(1988)116<2725:POTAFE > 2.0.CO;2.

Seiler, C., and F. W. Zwiers, 2016: How well do CMIP5 climate models reproduce explosive cyclones in the extratropics of the Northern Hemisphere? Climate Dyn., 46, 1241-1256, https:// doi.org/10.1007/s00382-015-2642-x.

Serreze, M. C., 1995: Climatological aspects of cyclone development and decay in the Arctic. Atmos.-Ocean, 33, 1-23, https:// doi.org/10.1080/07055900.1995.9649522.

Sinclair, M. R., 1994: An objective cyclone climatology for the Southern Hemisphere. Mon. Wea. Rev., 122, 2239-2256, https:// doi.org/10.1175/1520-0493(1994)122<2239:AOCCFT>2.0.CO;2.

- 1997: Objective identification of cyclones and their circulation intensity, and climatology. Wea. Forecasting, 12, 595-612, https:// doi.org/10.1175/1520-0434(1997)012<0595:OIOCAT>2.0.CO;2.

Takayabu, I., H. Niino, M. D. Yamanaka, and S. Fukao, 1996: An observational study of cyclogenesis in the lee of the Japan central mountains. Meteor. Atmos. Phys., 61, 39-53, https:// doi.org/10.1007/BF01029710.

Uccellini, L. W., and P. J. Kocin, 1987: The interaction of jet streak circulations during heavy snow events along the east coast of United States. Wea. Forecasting, 2, 289-308, https://doi.org/ 10.1175/1520-0434(1987)002<0289:TIOJSC > 2.0.CO;2.

—, D. Keyser, K. F. Brill, and C. H. Wash, 1985: The Presidents' Day cyclone of 18-19 February 1979: Influence of upstream trough amplification and associated tropopause folding on rapid cyclogenesis. Mon. Wea. Rev., 113, 962-988, https://doi.org/ 10.1175/1520-0493(1985)113<0962:TPDCOF $>2.0 . C O ; 2$.

Wang, C.-C., and J. C. Rogers, 2001: A composite study of explosive cyclogenesis in different sectors of the North Atlantic. Part I: Cyclone structure and evolution. Mon. Wea. Rev., 129, 1481-1499, https://doi.org/10.1175/1520-0493(2001)129<1481: ACSOEC $>2.0 . C O ; 2$.

Wash, C. H., J. E. Peak, W. E. Calland, and W. A. Cook, 1988: Diagnostic study of explosive cyclogenesis during FGGE. Mon. Wea. Rev., 116, 431-451, https://doi.org/10.1175/ 1520-0493(1988)116<0431:DSOECD>2.0.CO;2.

Whitaker, J. S., and C. A. Davis, 1994: Cyclogenesis in a saturated environment. J. Atmos. Sci., 51, 889-907, https://doi.org/10.1175/ 1520-0469(1994)051<0889:CIASE >2.0.CO;2.

Yoshida, A., and Y. Asuma, 2004: Structures and environment of explosively developing extratropical cyclones in the northwestern Pacific region. Mon. Wea. Rev., 132, 1121-1142, https://doi.org/ 10.1175/1520-0493(2004)132<1121:SAEOED > 2.0.CO;2.

Yoshiike, S., and R. Kawamura, 2009: Influence of wintertime largescale circulation on the explosively developing cyclones over the western North Pacific and their downstream effects. J. Geophys. Res., 114, D13110, https://doi.org/10.1029/2009JD011820.

Zehnder, J., and D. Keyser, 1991: The influence of interior gradients of potential vorticity on rapid cyclogenesis. Tellus, $\mathbf{4 3 A}$, 198-212, https://doi.org/10.3402/tellusa.v43i3.11927.

Ziv, B., and N. Paldor, 1999: The divergence fields associated with timedependent jet streams. J. Atmos. Sci., 56, 1843-1857, https://doi.org/ 10.1175/1520-0469(1999)056<1843:TDFAWT>2.0.CO;2. 